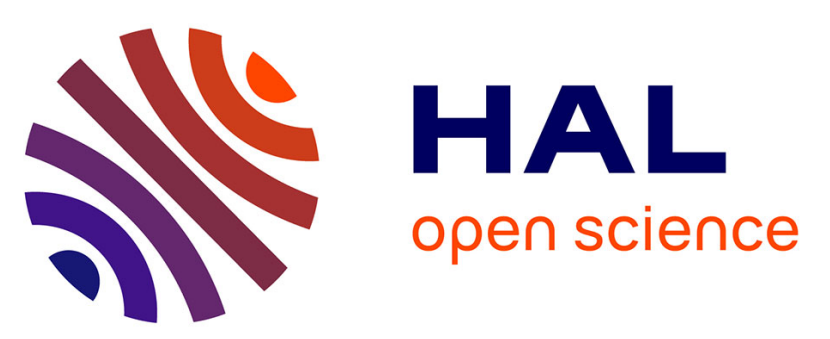

\title{
Unilateral CO2 Reduction Policy with More Than One Carbon Energy Source
}

Julien Daubanes, Fanny Henriet, Katheline Schubert

\section{To cite this version:}

Julien Daubanes, Fanny Henriet, Katheline Schubert. Unilateral CO2 Reduction Policy with More Than One Carbon Energy Source. Journal of the Association of Environmental and Resource Economists, 2021, 8 (3), 10.1086/711897 . hal-03093955

\section{HAL Id: hal-03093955 https://hal.science/hal-03093955}

Submitted on 28 Jan 2022

HAL is a multi-disciplinary open access archive for the deposit and dissemination of scientific research documents, whether they are published or not. The documents may come from teaching and research institutions in France or abroad, or from public or private research centers.
L'archive ouverte pluridisciplinaire $\mathbf{H A L}$, est destinée au dépôt et à la diffusion de documents scientifiques de niveau recherche, publiés ou non, émanant des établissements d'enseignement et de recherche français ou étrangers, des laboratoires publics ou privés. 


\section{CEsifo \\ WORKING

\section{Unilateral CO2 Reduction Policy with More Than One Carbon Energy Source}

Julien Xavier Daubanes, Fanny Henriet, Katheline Schubert 


\section{Impressum:}

CESifo Working Papers

ISSN 2364-1428 (electronic version)

Publisher and distributor: Munich Society for the Promotion of Economic Research - CESifo

$\mathrm{GmbH}$

The international platform of Ludwigs-Maximilians University's Center for Economic Studies and the ifo Institute

Poschingerstr. 5, 81679 Munich, Germany

Telephone +49 (0)89 2180-2740, Telefax+49 (0)89 2180-17845, email office@cesifo.de

Editor: Clemens Fuest

https://www.cesifo.org/en/wp

An electronic version of the paper may be downloaded

- from the SSRN website: www.SSRN.com

- from the RePEc website: $\quad$ www.RePEc.org

- from the CESifo website: https://www.cesifo.org/en/wp 


\title{
Unilateral CO2 Reduction Policy with More Than One Carbon Energy Source
}

\begin{abstract}
We examine an open economy's strategy to reduce its carbon emissions by replacing its consumption of coal—very carbon intensive-with gas-less so. Unlike the standard theoretical approach to carbon leakage, we show that unilateral CO2 reduction policies generate a higher leakage rate in the presence of more than one carbon energy source, and may turn counterproductive, ultimately increasing world emissions. We establish testable conditions as to whether a unilateral tax on domestic $\mathrm{CO} 2$ emissions increases the domestic exploitation of gas, and whether such a strategy increases global emissions. We also characterize this strategy's implications for climate policy in the rest of the world. Finally, we present an illustrative application of our results to the US.
\end{abstract}

JEL-Codes: Q580, H730, F180.

Keywords: unilateral climate policy, carbon emission reduction, shale gas, gas-coal substitution, coal exports, carbon leakage, US policy, counter-productive policy.

\author{
Julien Xavier Daubanes \\ University of Geneva / Switzerland \\ julien.daubanes@unige.ch \\ Fanny Henriet \\ Paris School of Economics (CNRS) / France \\ fanny.henriet@psemail.eu \\ Katheline Schubert \\ Paris School of Economics \\ University Paris I / France \\ schubert@univ-paris1.fr
}

\begin{abstract}
September 2020
We thank participants at various seminars and conferences: CESifo Munich; University of Oxford; Ecole Polytechnique; Shale Gas and Energy Transition Paris Workshop; SURED Banyuls Conference; FAERE Bordeaux Conference; University of Montpellier; Montreal Environment and Resource Economics Workshop; NAERE Helsinki Workshop; University of Tartu; Conference of the Danish Environmental Economic Council; University of Copenhagen; University Paris Nanterre; University of Geneva; WCERE Gothenburg Conference; University of Maryland; Environmental and Resource Economics Workshop at University of California, Santa Barbara; Toulouse School of Economics. Particular thanks to Hassan Benchekroun, Gérard Gaudet, John Hartwick, Martin Hansen, Matthew Kotchen, Pierre Lasserre, Justin Leroux, Chuck Mason, Rick van der Ploeg, Fabien Prieur, Steve Salant, Charles Séguin, Natacha Raffin, and Jean-Charles Rochet. We are also very grateful to Co-Editor Stephen Holland and three anonymous referees for their suggestions that contributed to significantly improve the paper. Financial support from the Agence Nationale de la Recherche (ANR-16-CE03-0011) and the CESifo is gratefully acknowledged.
\end{abstract}




\section{Introduction}

Natural gas is the fossil fuel that releases the least CO2 when burned. Now more than ever, it is hoped that a large replacement of very carbon intensive fuels by shale gas can help reduce carbon emissions and, therefore, significantly mitigate the urgent climate problem. ${ }^{1}$ An increasing number of top CO2 emitting countries that are endowed with substantial shale gas deposits plan to meet their emission reduction commitments by promoting this resource; among them, the US, Russia, China, the UK and, more recently, Japan. This substitution is mostly manifest in the power generation sector in which electricity can be economically produced from both steam coal and natural gas. In a sufficiently long-run perspective, over which the appropriate infrastructure can be built, gas can virtually replace coal and other traditional fuels for all uses.

However, two important aspects of the rise of shale gas have raised serious questions about its climate impact. The first-and most obvious - one concerns the net relative contribution of gas to global warming, once the leakage of methane at the production level is taken into account. This first aspect has been addressed in the field of natural sciences and raises specific regulatory challenges. ${ }^{2}$ Our analysis deals with the second, main, concerning aspect of the rise of gas: the international coal leakage that it induces.

This concern may be explained as follows. On the one hand, the well developed international competitive market for coal implies a particularly high leakage potential (Light, Kolstad, and Rutherford, 1999). On the other hand, the transport of gas is highly challenging and hardly adjustable, which explains that increased gas production is virtually all consumed where it is produced (Arezki, Fetzer, and Pisch, 2017). ${ }^{3}$ As a consequence, the domestic replacement of coal by shale gas releases amounts of tradable coal, whose supply contributes to increase emissions in the rest of the world. The rise of

\footnotetext{
${ }^{1}$ On the potential role of gas in climate policy, see Jacoby, O'Sullivan, and Paltsev (2011). This role has also been supported by the industry — see the June 1, 2015 joint letter of BP, BG Group, Eni, Statoil and Total to the UN, available at https://unfccc.int/news/major-oil-companies-letter-to-un.

${ }^{2}$ For a recent study on the low cost of abating methane emissions due to fracking, see Marks (2018). Our analysis will take into account the absence of scientific consensus around the climate impact of gas.

${ }^{3}$ As Arezki et al. (2017, page 35) put it "Liquefaction at origin and re-gasification at destination are the only other means for long distance trade. However, the laws of physics governing liquefaction and re-gasification imply an exogenously given lower bound on transport costs, which is substantial . . . Add to that the costs of transportation, storage and operating. Natural gas markets are much less integrated compared to markets for other fossil fuels."
} 
gas may not be compensated by a sufficient decrease in coal use to reduce CO2 emissions globally.

For example, our concern is well illustrated by recent developments in the US energy sector. ${ }^{4}$ First, the EPA regulation of CO2 emissions since 2011 has explicitly supported the development of gas and directly contributed to accelerate its effective substitution for coal in the US power sector depicted in Figure 1(a). ${ }^{5}$ Second, this substitution has contributed - among other factors - to the reduction of the US CO2 emissions (Feng et al., 2015, and Kotchen and Mansur, 2016) illustrated in Figure 1(b). Third, the gas boom in the US has been concomitant with an increase in net US coal exports, as shown by Figure 1(c), which reached $15 \%$ of the US coal consumption in 2019. Eyer (2015), for example, finds that around $75 \%$ of coal that has been displaced in the US electricity sector due to the rise of gas has been exported. Finally, these developments are likely to persist due to both the maintained pressure towards $\mathrm{CO} 2$ reduction by US states and corporations, ${ }^{6}$ and the support to gas and to US coal exports by the Trump Administration. ${ }^{7}$

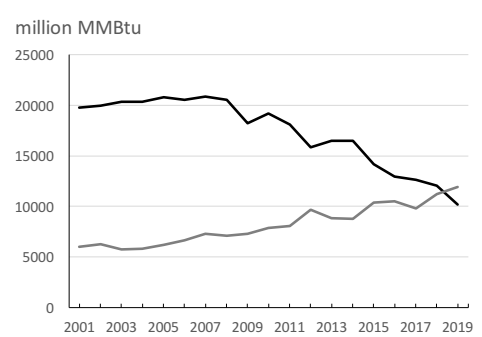

(a) Consumption of coal (black) and gas (grey) by the power generation sector (million MMBtu)

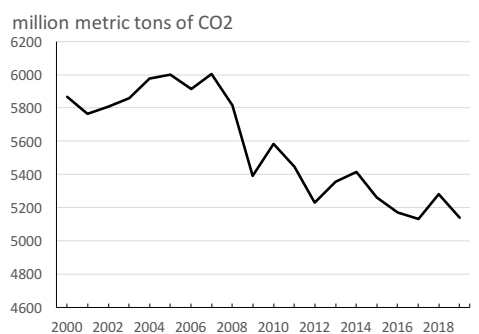

(b) CO2 emissions from energy consumption (million metric tons)

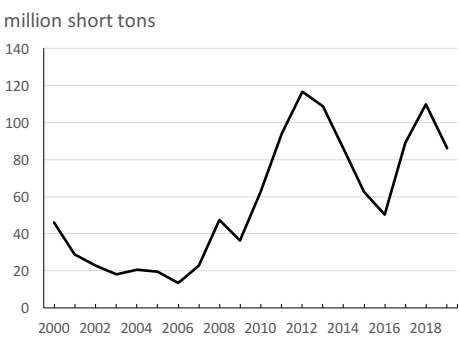

(c) Net exports of coal to the rest of the world (million short tons)

Figure 1: US example (Source: US Energy Information Administration ${ }^{8}$ )

\footnotetext{
${ }^{4}$ In recent years, the US was the second biggest carbon emitting economy, the most important gas producer, the third biggest coal producer and coal consumer, and, last but not least, the top coal reserve holder. See, for example, https://www.eia.gov/international/data/world.

${ }^{5}$ The Clean Air Act since 2011 and the US signature of the Paris Climate Agreement in 2016 engaged the US Federal Government in the reduction of CO2 emissions. To meet this objective, the previous US Administration's plan was to rely on the promotion of gas production-see, e.g., President Obama's June 25, 2013 speech, available at https ://obamawhitehouse.archives.gov/the-press-office/2013/06/ 25/remarks-president-climate-change - although the development of gas was already manifest in the aftermath of the early 2000s' "fracking" revolution.

${ }^{6}$ See, e.g, The Economist, June 5, 2017.

${ }^{7}$ See, e.g., President Trump's June 29, 2017 speech, available at https://www.whitehouse.gov/ briefings-statements/remarks-president-trump-unleashing-american-energy-event/.

${ }^{8}$ The data used here are available at https://www.eia.gov/electricity/data.php, for Figure 1(a), https://www.eia.gov/totalenergy/data/annual/index.php, for Figure 1(b), and https:// www.eia.gov/coal/data.php, for Figure 1(c), in which net exports are obtained by taking the difference between total exports and total imports.
} 
At the global level, the large replacement of coal by gas in various gas-rich regions over the past years has often been celebrated as a progress in the fight against climate change. ${ }^{9}$ However, it has not been accompanied with a decline in coal use worldwide. Indeed, at the same time, a number of other countries have increased the share of coal in their power mix,${ }^{10}$ so that global coal consumption has not decreased for the past ten years. ${ }^{11}$ As a result, total $\mathrm{CO} 2$ emissions due to both coal and gas have increased over the same period.

This problem deserves a particular attention in the context of the current energy landscape. Indeed, in the aftermath of the Paris Climate Agreement, governments will have to rely on unilateral initiatives to meet their respective emission reduction targets.

In this paper, we examine an open economy that relies on more than one carbon energy source, and we consider a unilateral policy aimed to reduce the CO2 emissions generated by the domestic use of these sources. ${ }^{12}$ We tackle the questions whether the promotion of cleaner energy sources, like gas, can help reduce domestic and global emissions.

Our analysis shows that, with multiple carbon-generating energy sources, a unilateral carbon penalty not only reduces the total production of the most polluting sources, it may also boost the domestic production of cleaner sources like gas to replace the domestic consumption of the former, whose exports increase. In fact, this boost induces a higher leakage rate relative to situations in which energy sources are equally polluting, as in models with a single, aggregate carbon source. Moreover, this boost may be of such an extent that it compensates, at the global level, the carbon reduction due to the global contraction in the most polluting sources; in this case, the total quantity of carbon is increased and, therefore, carbon leakage from the carbon reducing economy is augmented to more than $100 \%$. Such a possibility can be interpreted as the leakage counterpart of the "green paradox" (Sinn, 2008, among many others, e.g., van der Ploeg and Withagen,

\footnotetext{
${ }^{9}$ See, e.g., Bloomberg, June 11, 2019, available at https://www.bloomberg.com/news/articles/ 2019-06-11/gas-price-plunge-signals-greener-start-for-2019-in-u-s-and-eu.

${ }^{10}$ According to Sebi (2019), twenty countries in Africa, Central America, the Middle-East, and Asia have recently turned to this energy source.

${ }^{11}$ Global coal consumption has even increased in 2017 and 2018; see https://yearbook.enerdata. net/coal-lignite/coal-world-consumption-data.html.

${ }^{12}$ We focus on domestic policies that only target $\mathrm{CO} 2$ emissions generated by the domestic use of carbon energy sources-i.e., that do not penalize the carbon energy production that is exported to the rest of the world-because this is how the most significant policy commitments and initiatives are designed: e.g., countries' Nationally Determined Contributions under the Paris Agreement, the US EPA regulation of $\mathrm{CO} 2$ emissions under the Clean Air Act, the EU-ETS system, among many others.
} 
2014). We establish testable conditions as to whether a unilateral tax on domestic CO2 emissions increases the domestic exploitation of cleaner energy sources, and whether such a strategy increases global emissions, and we present an illustrative application of these results to the US.

The bulk of research on carbon leakage has been carried out in rich multi-regional, multi-level CGE analyses - see, for example, Felder and Rutherford (1993), among many others more recently - and delivers, in general, a rather optimistic message: It predicts low rates of carbon leakage, ranging from 10 to 30\%, meaning that unilateral CO2 reductions are only limited, but never offset, by carbon leakage, and therefore unambiguously effective. Some studies have specifically highlighted the general-equilibrium mechanisms through which leakage is reduced and may even turn negative - see, e.g., Baylis, Fullerton, and Karney (2014) on the mobility of clean inputs, and Gerlagh and Kuik (2014) on energy-saving technical change. This optimistic view has been challenged by revisiting the assumptions underlying these models. Babiker (2005) shows that the leakage rate may exceed $100 \%$ in the presence of increasing returns to scale in internationally mobile energy-intensive industries. Moreover, Eichner and Pethig (2011) and Ritter and Schopf (2014) stress that intertemporal substitution of fossil-fuel energy sources may generate more than $100 \%$ leakage rates.

Our paper's novelty is to suggest and examine another reason why current unilateral policies may be counterproductive: the presence of several energy sources with various CO2 intensities replacing each other. Unlike Babiker (2005), we do not consider the international mobility of energy-intensive industries - for example, the power generation industry is not mobile - and, therefore, we focus on the international energy market. Neither do we rely on the Hotelling structure of Eichner and Pethig (2011). ${ }^{13}$

Our analysis sharply contrasts with the standard approach in the theoretical literature on carbon leakage which assumes, for simplicity, a single carbon energy source - see, among many examples, Markusen (1975), Hoel (1994), or Harstad (2012). The difference may be explained as follows. With a single source of carbon, any carbon penalty-be it unilateral-causes its total supply to contract; leakage, in that case, reallocates the

\footnotetext{
${ }^{13}$ Our results, however, directly carry over to a Hotelling model in which energy resources are first developed and then extracted over time, as explained in Subsection V.A.
} 
consumption of a smaller total carbon quantity. We contribute to this literature by showing that the mere multiplicity of polluting sources increases the leakage rate.

Our paper is also complementary to the resource economics literature that has dealt with the coexistence of several polluting energy sources, but in closed economy frameworks of analysis - see, among other papers, Chakravorty, Moreaux, and Tidball (2008), Coulomb and Henriet (2017), and Henriet and Schubert (2019).

At the intersection of two previous strands of literature, Michielsen's (2014) and Fischer and Salant's (2017) theoretical and simulated models, and a variety of CGE models, ${ }^{14}$ come close to our analysis by examining unilateral climate policies in the presence of various substitutable carbon energy sources. In these models, in general, the mechanism that we highlight applies, although it has remained hidden by particular choices of parameters. ${ }^{15}$ At the same time, in line with our results, the multidimensional sensitivity analysis of Burniaux and Oliveira Martins (2012) in a much richer general-equilibrium model highlights the crucial role of the coal supply elasticity. With respect to this literature, we derive new analytical results that encompass a larger set of parameter values, which seems sensible to describe a coal and gas industry that has dramatically changed over the past decade.

Finally, our paper complements a number of studies focusing on the case of the US coal-gas policy-induced substitution. Although the increase in US coal exports has drawn attention (e.g., Knittel, Metaxoglou, and Trindade, 2016), ${ }^{16}$ existing analyses mostly focus on developments within the US economy-e.g., Burtraw et al. (2014), Knittel, Metaxoglou, and Trindade (2015), Cullen and Mansur (2017), and Linn and Muehlenbach (2018). A recent exception is due to Knittel et al. (2018) who estimate a structural model that links the domestic to the international coal market. Their results suggest that US coal exports have not increased the total quantity of coal used worldwide. In relation to this paper's estimation, our approach allows us, for example, to examine the possibility that the domestic CO2 reduction policy is counterproductive even though the

\footnotetext{
${ }^{14}$ For an example of such models, see Château, Dellink, and Lanzi (2014).

${ }^{15}$ For example, in a model that is slightly different from ours, Michielsen (2014) restricts his analysis to extreme supply elasticity values of either zero or infinity, concluding that the spatial leakage rate cannot exceed $100 \%$.

${ }^{16} \mathrm{See}$ also Meredith Fowlie's contribution to the blog of the Energy Institute at Haas, Berkeley, available at https://energyathaas.wordpress.com/2014/07/28/ will-coal-exports-abroad-offset-hard-won-carbon-reductions-at-home/.
} 
total quantity of coal is reduced. In particular, our analysis highlights, and our application to the US illustrates, the critical role of various energy demand and supply elasticities as well as energy sources' CO2 intensities in the effectiveness of domestic climate policies.

To address our problem, the main part of the paper examines a highly stylized open economy, purposely considering the minimal set of ingredients involved. There are two regions: the home country and the rest of the world. The home country relies on two substitutable carbon energy inputs: coal-more carbon intensive - and gas-less so. In order to focus the analysis on coal exports, we assume that the rest of the world cannot use the home country's gas but may trade coal with the home economy. ${ }^{17}$ In each region, there is a single representative energy consumer and a single firm representative of the sector supplying carbon energy sources; their demands and supplies depend on prices only. The model features policy-induced leakage of carbon emission, which results from both changes in the production of carbon energy inputs, and the international reallocation of their consumption. Our main analysis rests on a simple static representation of the energy market, in the spirit, for example, of Hoel (1994) and Harstad (2012).

We also present a variety of extensions to explain how our analysis accommodates more complex environments, stressing the following aspects that, although not central to our theory, deserve attention: ( $\imath$ ) carbon resources' scarcity and their dynamic ex-

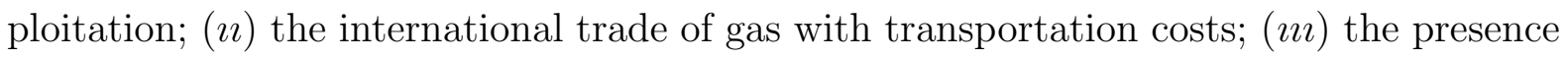
of gas in the rest of the world; $(\imath v)$ the presence of other non-carbon energy sources; $(v)$ technical progress in the production of gas and non-carbon energy sources; $(v \imath)$ the limited substitutability between carbon energy sources.

The rest of the article is structured as follows. Section II presents our model. Section III examines the effect of a unilateral CO2 reduction policy on domestic and global emissions, and implications for climate policy in the rest of the world. Among other results, the analysis yields testable conditions establishing in which contexts the promotion of natural gas is justified from the perspective of an individual country's emission objective and from a global perspective. Section IV illustrates these formulas with a numerical application to the case of the US. Section V discusses various extensions. Section VI

\footnotetext{
${ }^{17}$ This simplifying assumption is neither critical-see Subsection V.B-nor unrealistic. As Arezki et al. (2017) recently reminded us - see also footnote 3-technical difficulties to trade gas imply that gas markets are hardly integrated.
} 
concludes.

\section{A Simple Model of an Open Economy Using Coal and Gas}

\section{A. Basics}

Regions. There are two regions. The domestic open economy of interest will be called "Home," and variables related to this country will accordingly be denoted by the superscript "H." The rest of the world will be treated as a single open economy which will be called "Foreign," and variables related to it will be denoted by the superscript "F."

Coal supply. In each of the two regions, there is a price-taking representative firm supplying coal. Coal being freely tradable across regions, competitive markets will establish a single international coal producer price $p_{c}{ }^{18}$ The Home and Foreign coal supplying firms respectively produce amounts $S_{c}^{H}$ and $S_{c}^{F}$ - expressed in energy units-determined as supply functions:

$$
S_{c}^{H}=S_{c}^{H}\left(p_{c}\right)
$$

and

$$
S_{c}^{F}=S_{c}^{F}\left(p_{c}\right)
$$

which are both assumed nonnegative, differentiable and strictly increasing for all $p_{c} \geq 0$.

Gas supply. For simplicity, gas is only produced in the Home country by a price-taking representative firm, which does not export it. ${ }^{19}$ Its production $S_{g}$-expressed in energy units - is determined as a supply function of the domestic producer price of gas $p_{g}$

$$
S_{g}=S_{g}\left(p_{g}\right)
$$

which is assumed nonnegative, differentiable and strictly increasing for all $p_{g} \geq 0$.

Energy demand by the Foreign country. For simplicity, the rest of the world only relies on the coal energy source: ${ }^{20}$ There is a price-taking representative consumer of electric energy in the Foreign country, and electricity is solely produced from coal through a

\footnotetext{
${ }^{18}$ In Subsection V.B, we present an extension of this model that features transportation costs.

${ }^{19}$ In Subsection V.B, we explain how the analysis accommodates the possibility that gas is exported.

${ }^{20}$ The foreign coal demand function $D^{F}$ may be interpreted as a residual demand after other locally produced non-carbon energy sources have been consumed, with no implications on our analysis. As far as the presence of gas in the Foreign country is concerned, see the discussion of Subsection V.C highlighting that the analysis' extension to foreign gas leads to similar qualitative conclusions.
} 
linear technology which, in energy units, is "one-for-one." Therefore, the Foreign country's energy consumer price is equal to $p_{c}$, and its coal consumption $D^{F}$ is determined as an energy demand function

$$
D^{F}=D^{F}\left(p_{c}\right)
$$

which is assumed nonnegative, differentiable and strictly decreasing for all $p_{c} \geq 0$.

Energy demand by the Home country. The domestic economy relies on both coal and gas: There is a competitive representative consumer of electric energy in the Home country, and electricity can be produced equivalently from coal or gas through a onefor-one energy transformation technology. Since coal and gas are perfectly substitutable, competitive markets will establish a single consumer price for the final energy, irrespective of the source of energy. We will denote this price by $p$. Therefore, the Home country's consumption $D^{H}$ of coal and gas is determined as an energy demand function

$$
D^{H}=D^{H}(p)
$$

which is assumed nonnegative, continuous and strictly decreasing for all $p \geq 0 .{ }^{21}$ The domestic consumption $D^{H}$ corresponds to the consumption of the domestically produced gas $S_{g}$ and a residual consumption of coal

$$
D_{c}^{H}=D^{H}-S_{g}
$$

\section{B. Laissez-Faire Equilibrium}

By assumption, the energy market is competitive. In this subsection, we assume no policy. Public policy will be introduced in the next section.

As will be clear shortly below, our analysis will focus on the empirically relevant equilibrium in which the Home economy produces electricity from coal and gas at the same time. Since the latter are assumed perfectly substitutable in the Home economy, such an interior equilibrium is characterized by the following no-arbitrage equality, ${ }^{22}$

\footnotetext{
${ }^{21}$ This demand function may be interpreted as the residual energy demand after other-e.g., alternative - energy sources have been used.

${ }^{22}$ In practice, as early noticed by Hoel (1984), energy sources are substitutable for some but not all uses. In industries in which coal and gas are substitutable - as, for example, the power generation sectorcoal and gas inputs are not perfectly substitutable at the plant level because power plants are typically fuel specific, but they are so at the industry level in a sufficiently-long-term perspective that allows the building of new coal- and gas-fired power plants. That is why, despite the fact that the US power generation sector has been investing in new coal- and gas-fired plants simultaneously in the past few
} 
relating the domestic consumer energy price to the domestic producer prices of coal and gas:

$$
p=p_{c}=p_{g}
$$

In the rest of the paper, all variables or functions will be evaluated at the market equilibrium.

In this context, the equilibrium price $p$ is characterized by the balance between energy demand and supply at the world level:

$$
D^{H}(p)+D^{F}(p)=S_{c}(p)+S_{g}(p)
$$

where the function $S_{c} \equiv S_{c}^{H}+S_{c}^{F}$ denotes world coal supply.

First, we assume that $D^{H}(0)+D^{F}(0)>S_{c}(0)+S_{g}(0)$ and $\lim _{p \mapsto+\infty}\left[D^{H}(p)+D^{F}(p)\right]<$ $\lim _{p \mapsto+\infty}\left[S_{c}(p)+S_{g}(p)\right]$, so as to eliminate the uninteresting situation in which there exists no equilibrium with non-zero energy consumption. Since the left-hand side and righthand side of (2) are strictly decreasing and increasing, respectively, $p>0$ is uniquely defined.

Second, we assume that the residual demand for coal in the Home country $D^{H}(p)-$ $S_{g}(p)>0$ is non-zero in the equilibrium, validating our focus on the interior domestic allocation of coal and gas. Therefore, the equilibrium may be characterized by the interior balance between the domestic residual demand for coal $D^{H}-S_{g}$ and the world residual coal supply after the foreign demand is served $S_{c}-D^{F}$. This is the way this equilibrium, and others, will be depicted in Figures 2 and 3 further below.

The equilibrium price $p$ defined by (2) determines all other variables: domestic gas production $S_{g}$; domestic and foreign coal production $S_{c}^{H}$ and $S_{c}^{F}$; domestic electricity consumption from coal and gas $D^{H}$, and, therefore, domestic coal consumption $D_{c}^{H}=$ $D^{H}-S_{g}$; rest-of-the-world coal consumption $D^{F}$.

Note that the Home country's net exports of coal $\left(D^{H}-S_{g}\right)-S_{c}^{H}$ may be positive or negative - that is, the Home country may be a net exporter or importer of coal.

years, the equality between the price of coal and the price of gas for an equivalent amount of power was not exactly observed. It is important to note, nevertheless, that the respective costs of using these two fuels have been rapidly converging since 2005, whether or not other operating expenses are integratedsee, e.g., http://www.eia.gov/electricity/annual/html/epa_08_04.html. This convergence reflects that the short-run arbitrage between the two substitutable energy sources tends to vanish in the long run. For cases in which energy sources are imperfect substitutes, see the extension presented in Subsection V.F. 


\section{Domestic CO2 Reduction Policy, Gas Promotion and World CO2 Emissions}

In this section, we examine a policy aimed to reduce $\mathrm{CO} 2$ emissions generated in the Home country by the domestic use of coal and gas.

\section{A. CO2 Emissions and Domestic CO2 Reduction Policy}

First, we assume that, per unit of energy, coal consumption and gas consumption generate respectively $\theta_{c}$ and $\theta_{g}$ units of $\mathrm{CO} 2$, and that coal is more $\mathrm{CO} 2$ intensive than gas:

$$
\theta_{c} \geq \theta_{g}>0
$$

Domestic CO2 emissions, therefore, amount to

$$
e^{H}=\theta_{c} D_{c}^{H}+\theta_{g} S_{g}
$$

Second, we consider the following domestic CO2 reduction policy: We assume that a $\mathrm{CO} 2$ unit fee $\tau^{H} \geq 0$ is applied to CO2 emissions generated in the Home country. This domestic CO2 fee is a simple and meaningful way to capture all kinds of policies that penalize the use of carbon energy sources, ranging from implicit penalties induced by regulatory constraints to explicit carbon pricing such as a carbon tax or a competitive market for CO2 emission rights.

In turn, the domestic CO2 price $\tau^{H}$ amounts to varying taxes on the use of coal and gas, proportional to their CO2 intensity: With the tax, the additional unit cost of using coal is $\theta_{c} \tau^{H}$ and the additional unit cost of using gas is $\theta_{g} \tau^{H}$. Therefore, the consumer prices of coal and gas in the Home country become respectively $p_{c}+\theta_{c} \tau^{H}$ and $p_{g}+\theta_{g} \tau^{H}$ and the no-arbitrage condition (1) prevailing in equilibrium becomes:

$$
p=p_{c}+\theta_{c} \tau^{H}=p_{g}+\theta_{g} \tau^{H}
$$

This condition relates the equilibrium producer prices for coal $p_{c}$ and gas $p_{g}$ to the equilibrium domestic consumer price for energy $p$ and the domestic CO2 price $\tau^{H}$. Therefore, producer prices are now given by $p_{c}=p-\theta_{c} \tau^{H}$ and $p_{g}=p-\theta_{g} \tau^{H}$.

Given the domestic policy, equilibrium prices must balance supply and demand on the world energy market as in Section II. Using expression (4), and keeping in mind that, 
absent any policy in the Foreign country, the consumer price of coal in the rest of the world is equal to its producer price $p_{c}$, the equilibrium condition (2) becomes

$$
D^{H}(p)+D^{F}\left(p-\theta_{c} \tau^{H}\right)=S_{c}\left(p-\theta_{c} \tau^{H}\right)+S_{g}\left(p-\theta_{g} \tau^{H}\right)
$$

Appendix A shows the following property.

\section{Proposition 1 (Existence and uniqueness of the interior equilibrium) If $\tau^{H}>$}

0 is not too high, the equilibrium exists, is interior, and is characterized by (5), which has a unique solution $p$; this solution determines producer prices $p_{c}$ and $p_{g}$ by (4), and, therefore, all equilibrium quantities.

In order to obtain explicit analytical results, the rest of the analysis will focus on an infinitesimal increase in the domestic fee $\tau^{H} \geq 0$, starting from the laissez-faire situation in which $\tau^{H}=0$.

Prior to examining gas production and world emissions, we present preliminary findings that will turn out to be useful later on to interpret our results. The textbook analysis of tax incidence suggests that a tax on a commodity reduces its equilibrium quantity by increasing its consumer price. In our model with more than one carbon energy source, the following lemma - shown in Appendix A - confirms that the domestic CO2 tax translates into a rise in the domestic consumer price for energy and a decrease in domestic (coal and gas) energy use.

In the rest of the paper, terms

$$
\xi_{X} \equiv|q d X / d q|>0
$$

will denote the absolute value of the elasticity of any function $X(q)$ with respect to its argument.

Lemma 1 (Domestic consumer energy price) The domestic CO2 reduction policy increases the domestic consumer price for energy $d p / d \tau^{H}>0$; this increase is more pronounced as the elasticity of the domestic energy demand $\xi_{D^{H}}$ is lower.

As is well known, when the energy demand is less elastic the tax incidence falls more on the demand side and less on the supply side. Accordingly, the domestic policy leads to 
a decrease in the domestic energy consumption $d D^{H} / d \tau^{H}=-\left(D^{H} \xi_{D^{H}} / p\right)\left(d p / d \tau^{H}\right)<0$ which is less pronounced as $\xi_{D^{H}}$ is lower.

Let us now turn to the incidence of the domestic policy on the production of coal and gas.

\section{B. Coal Production}

As far as coal is concerned, Appendix A verifies analytically that coal production is systematically reduced by the domestic CO2 reduction policy.

Lemma 2 (Coal production) The domestic CO2 reduction policy induces decreases in the domestic and foreign production of coal $d S_{c}^{H} / d \tau^{H}<0$ and $d S_{c}^{F} / d \tau^{H}<0$; these are more pronounced as $\xi_{S_{c}^{H}}, \xi_{S_{c}^{F}}, \xi_{D^{H}}$ and $\theta_{c}$ are higher, and as $\xi_{D^{F}}$ and $\theta_{g}$ are lower.

In line with the textbook analysis of tax incidence, the producer price of coal $p_{c}$ is reduced by the domestic policy; the effect on the producer price is more pronounced when the domestic energy demand is less elastic. Moreover, coal being tradable, its producer price is international and reacts less strongly as the foreign demand is more elastic. The effect on coal production follows through immediately. Finally, the change in coal production is intuitively less pronounced as coal supply is less sensitive to $p_{c}$.

Moreover, the effect on the producer price of coal is more pronounced when coal is relatively more polluting. In fact, in the presence of more than one carbon energy source, coal production is reduced as it is the most polluting energy source. As far as gas is concerned, however, things are not so simple.

\section{Domestic Gas Production}

Gas is polluting, but less so than coal. For such a cleaner energy source, perhaps surprisingly, the producer price $p_{g}=p-\theta_{g} \tau^{H}$ may rise as a result of the carbon fee: The rise in the consumer energy price $p$ as per Lemma 1 may dominate the increase in the penalty on gas $\theta_{g} \tau^{H}$. In that case, domestic gas production $S_{g}$ increases.

In Appendix A, the following condition is obtained, where we make use of the notation

$$
r \equiv \frac{\theta_{c}-\theta_{g}}{\theta_{g}} \geq 0
$$

to denote the rate of increase in pollution from gas to coal, which indicates the relative 
cleanliness of the gas energy source.

Proposition 2 (Rise of gas) The domestic CO2 reduction policy induces domestic gas production $S_{g}$ to increase $\left(d S_{g} / d \tau^{H}>0\right)$ if and only if

$$
r>\frac{D^{H} \xi_{D^{H}}}{D^{F} \xi_{D^{F}}+S_{c} \xi_{S_{c}}} \equiv r_{0},
$$

as when the rate $r$ and the elasticities $\xi_{D^{F}}$ and $\xi_{S_{c}}$ are sufficiently high, and the elasticity $\xi_{D^{H}}$ is sufficiently low.

This proposition provides a testable condition according to which the reduction of domestic emissions in a gas producing country implies that more gas is produced. ${ }^{23}$ This condition relates, on the one hand, the rate of increase in pollution from gas to coal $r \geq 0$ with, on the other hand, demand and supply price elasticities and market shares evaluated at the laissez-faire equilibrium.

For any observed elasticities and market shares, Proposition 2 tells that more gas should be produced when gas is sufficiently less CO2 intensive than coal. For example, in the limit case in which gas would tend to be CO2 free $\left(\theta_{g} \mapsto 0\right), r$ at the left-hand side of (7) would tend to be infinitely high, so that the condition would be systematically satisfied. Indeed, in a model in which only one of two perfectly substitutable energy sources is polluting, the reduction of pollution commands to increase the production of the non-carbon substitute. Also for example, if coal and gas were equally polluting $(r=0)$, the fact that the right-hand side of $(7)$ is nonnegative implies that the condition would never be satisfied. Indeed, in this limit case, there would be a single homogeneously polluting energy source with no substitute, requiring that its production be reduced to decrease pollution.

However, for sensible values of CO2 intensities $\theta_{c}$ and $\theta_{g}$, whether condition (7) is satisfied and, therefore, gas production should increase, depends on the properties of the emission-reducing open economy, as reflected in the condition's right-hand-side threshold $r_{0}$. Perhaps interestingly, $r_{0}$ does not involve $\xi_{S_{g}}$ so that whether gas production should

\footnotetext{
${ }^{23}$ Were the production of gas increased exogenously - perhaps due to technical progress as, for example, during the US "fracking" revolution - the same condition (7) would indicate whether this rise would induce the Home country's CO2 emissions to increase or not. In other words, under condition (7), the Home economy's development of gas and its reduction of $\mathrm{CO} 2$ emissions go hand in hand, irrespective of whether the latter or the former is the cause of the change.
} 
increase or decrease does not depend on the elasticity of gas supply. Moreover, analysis of $r_{0}$ indicates that relying on gas to reduce $\mathrm{CO} 2$ emissions is most likely to be justified when the economy's energy consumption $D^{H}$ and its elasticity $\xi_{D^{H}}$ are low, in a world in which coal holds a large share of the energy market.

Condition (7) may be satisfied for some gas-producing countries and not for others, with different implications for the promotion of gas. For example, in Section IV, we will examine how Proposition 2 applies to the case of the US.

The following lemma identifies the role of demand and supply sensitivities in the policy-induced change in gas production.

Lemma 3 (Domestic gas production) When (7) is satisfied, the policy-induced increase in domestic gas production $d S_{g} / d \tau^{H}>0$ is more pronounced as $\xi_{D^{H}}$ and $\theta_{g}$ are lower and $\xi_{S_{g}}, \xi_{S_{c}}, \xi_{D^{F}}$ and $\theta_{c}$ are higher.

Indeed, as already noticed, when demand is less elastic, the tax incidence falls more on energy consumers as per Lemma 1 and, therefore, less on coal producers - as per Lemma 2 - as well as on gas producers. Lemma 3 is in line with the role of $\xi_{D^{H}}$ identified in Proposition 2: As the domestic energy demand becomes sufficiently inelastic, the domestic $\mathrm{CO} 2$ reduction policy induces gas production to increase. In the extreme case in which the domestic energy use tends to be perfectly insensitive to prices, for example, CO2 emissions can only be reduced by an increase in gas energy use at the expense of coal. Moreover, also in line with Proposition 2, the policy-induced increase in gas production is larger as gas is a cleaner energy source, and as coal supply and foreign energy demand are more elastic. Finally, the role of $\xi_{S_{g}}$ is more surprising: Despite the fact that the elasticity of gas supply does not affect whether gas production increases or not-as per Proposition 2 - when gas production increases, it does so according to its elasticity $\xi_{S_{g}}$.

\section{Domestic CO2 Emissions and CO2 Leakage Due to Coal Exports}

Clearly, the possibility that gas production may increase in the Home country does not mean that domestic emissions can increase. Combining effects characterized in previous results, Appendix A verifies that domestic emissions

$$
e^{H}=\theta_{c}\left(D^{H}-S_{g}\right)+\theta_{g} S_{g}
$$


systematically decrease as a result of an increase in $\tau^{H}$, as expected.

Let us now examine emissions in the rest of the world. Were the foreign coal demand $D^{F}$ perfectly price inelastic, as it might be in the short run, the rest of the world's CO2 emissions would never increase. In a medium- to long-term perspective over which coal demand becomes elastic, however, emissions $e^{F}=\theta_{c} D^{F}\left(p_{c}\right)$ are systematically increased as a result of the domestic CO2 reduction. ${ }^{24}$ In this context, as mentioned above, the domestic $\mathrm{CO} 2$ reduction policy necessarily reduces the producer price $p_{c}$ of the most carbon intensive coal energy, inducing a rise in the equilibrium use of coal $D^{F}$ in the rest of the world. This is so despite the fact that the decreased coal producer price $p_{c}$ induces a reduction in coal production $S_{c}^{H}$ and $S_{c}^{F}$ in both regions. This is the effect highlighted by a leakage analysis focusing on a single carbon energy source.

It follows that the net coal imports $D^{F}-S_{c}^{F}$ of the Foreign country, and, therefore, the net coal exports of the Home country in direction of the rest of the world $S_{c}^{H}-\left(D^{H}-S_{g}\right)$ increase systematically as a result of the domestic CO2 emission reduction. This stresses the central role of the latter, identified in the introduction in the case of the US.

The following corollary summarizes these results.

\section{Corollary 1 (Domestic CO2 emissions, coal exports and leakage)}

The domestic CO2 reduction policy induces:

1. A decrease $d e^{H} / d \tau^{H}<0$ in domestic CO2 emissions;

2. An increase in domestic coal exports to the rest of the world $d\left[S_{c}^{H}-\left(D^{H}-S_{g}\right)\right] / d \tau^{H}>0 ;$

3. An increase in the rest of world CO2 emissions (leakage) $d e^{F} / d \tau^{H}>0$.

To sum up, the policy-induced reduction in domestic CO2 emissions is, at least partly, compensated by the increase in emissions in the rest of the world due to increased domestic coal exports. In fact, in our model, this compensation may more than offset the domestic

\footnotetext{
${ }^{24}$ Although coal demand in the Foreign country can be interpreted as the residual demand for coal after some other local energy sources have been used, our simplifying formulation implies that $\mathrm{CO} 2$ emissions from these other sources are omitted, as if they were all non carbon sources. Taking into account the $\mathrm{CO} 2$ emissions generated by other carbon energy sources in the Foreign country would slightly modify the model, with no implications on our qualitative results. For example, Subsection V.C discusses the presence of gas in the Foreign country.
} 
CO2 reduction, ultimately causing world $\mathrm{CO} 2$ emissions to rise. In other words, unlike the leakage analysis with a single carbon energy source, the rate of CO2 leakage associated with the domestic CO2 reduction $\left(d e^{F} / d \tau^{H}\right) /\left(-d e^{H} / d \tau^{H}\right)$ may exceed $100 \%$.

\section{E. World CO2 Emissions and Domestic Policy's Effectiveness}

We now address the issue of the effectiveness of the domestic unilateral CO2 reduction policy.

To interpret our next results, it would be helpful to keep in mind that world emissions may be expressed as emissions generated by coal worldwide and emissions generated by gas in the domestic economy:

$$
e^{W}=e^{H}+e^{F}=\theta_{c} S_{c}+\theta_{g} S_{g}
$$

This means that a less-than-one leakage rate $\left(d e^{F} / d \tau^{H}\right) /\left(-d e^{H} / d \tau^{H}\right)$ occurs when and only when the potential increase in emissions generated by gas $\theta_{g} d S_{g} / d \tau^{H}$ does not exceed the reduction of emissions generated by coal $\theta_{c} d S_{c} / d \tau^{H}$.

To illustrate the issue before its full analysis, Figures 2 and 3 provide two different examples of how the domestic CO2 reduction policy may impact the equilibrium. First, both figures include the laissez-faire equilibrium, characterized by the equality between $D^{H}-S_{g}$, the domestic residual demand for coal, and $S_{c}-D^{F}$, the world residual coal supply after the foreign demand is served, as explained in Subsection II.B-variables evaluated in the laissez-faire are denoted by the superscript "LF." Second, both figures feature the equilibrium under a given domestic CO2 reduction policy $\tau^{H}$, where $\tau^{H}$ is considered sufficiently large for graphical purposes. With the tax, equilibrium prices $p, p_{g}$ and $p_{c}$ diverges from $p^{L F}$ in such a way as to ensure that $D^{H}(p)-S_{g}\left(p_{g}\right)=S_{c}\left(p_{c}\right)-D^{F}\left(p_{c}\right)$ holds, where $p=p_{c}+\theta_{c} \tau^{H}=p_{g}+\theta_{g} \tau^{H}$. Comparison with the laissez-faire equilibrium shows nonmarginal quantity changes $\Delta S_{c}=|G H|$ and $\Delta S_{g}=|E F|$, whose ratio should be compared to $|A B| /|C D|=\theta_{g} / \theta_{c}$ to assess the effect on world emissions. Indeed, $|A B| /|C D|<|G H| /|E F|$ is equivalent to $\theta_{c} \Delta S_{c}+\theta_{g} \Delta S_{g}>0$, that is that the leakage rate is more than one and the domestic CO2 reduction policy is counterproductive.

Both Figures 2 and 3 illustrate the possibility, identified in Proposition 2, that the domestic policy induces gas production to increase. Since the two figures differ by the sensitivity of $D^{F}$, they further show that the policy-induced rise in gas production and 
the decrease in coal production depend on the sensitivity of energy demand and supply functions, in line with Lemmas 2 and 3. Finally, Figure 3 presents a case in which the increase in emissions generated by gas exceeds the decrease in emissions generated by coal, so that world emissions increase, unlike Figure 2.

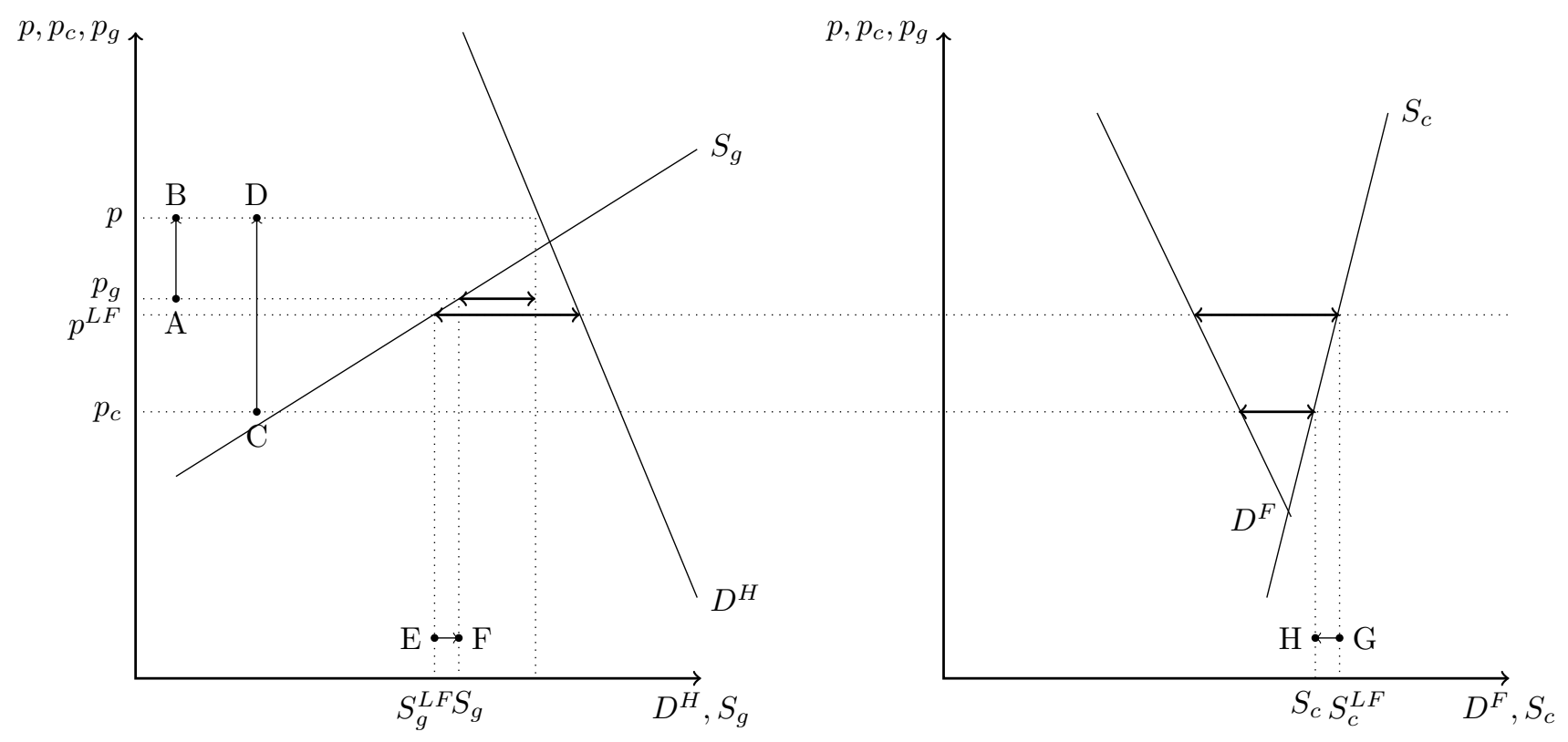

Figure 2: Decreased total emissions $e^{W}$

$|A B| /|C D|=\theta_{g} / \theta_{g}<\Delta S_{c} / \Delta S_{g}=|G H| /|E F|$ implies $\Delta e^{W}=\theta_{c} \Delta S_{c}+\theta_{g} \Delta S_{g}<0$

The leakage rate measures the effectiveness of the domestic CO2 reduction policy. In Appendix A, we obtain and examine the following formula.

Lemma 4 (Leakage rate) The domestic CO2 reduction policy induces a leakage rate

$$
\frac{\frac{d e^{F}}{d \tau^{H}}}{-\frac{d e^{H}}{d \tau^{H}}}=\frac{\frac{D^{H} \xi_{D^{H}}}{S_{g} \xi_{S_{g}}}(r+1)^{2}+(r+1) r}{\left(\frac{D^{H} \xi_{D^{H}}}{S_{g} \xi_{S_{g}}}(r+1)^{2}+r^{2}\right)\left(\frac{S_{c} \xi_{S_{c}}}{D^{F} \xi_{D^{F}}}+1\right)+\frac{D^{H} \xi_{D^{H}}}{D^{F} \xi_{D^{F}}}} .
$$

All other things being equal,

1. The leakage rate is higher as $\xi_{S_{g}}$ and $\xi_{D^{F}}$ are higher and $\xi_{D^{H}}$ and $\xi_{S_{c}}$ are lower;

2. Moreover, it is higher when $r>0$ than when $r=0$.

Our previous results shed light on the role of demand and supply elasticities identified in Lemma 4. Indeed, by Lemmas 2 and 3, less elastic domestic energy demand and more elastic gas supply and foreign energy demand imply that the policy-induced decrease in 


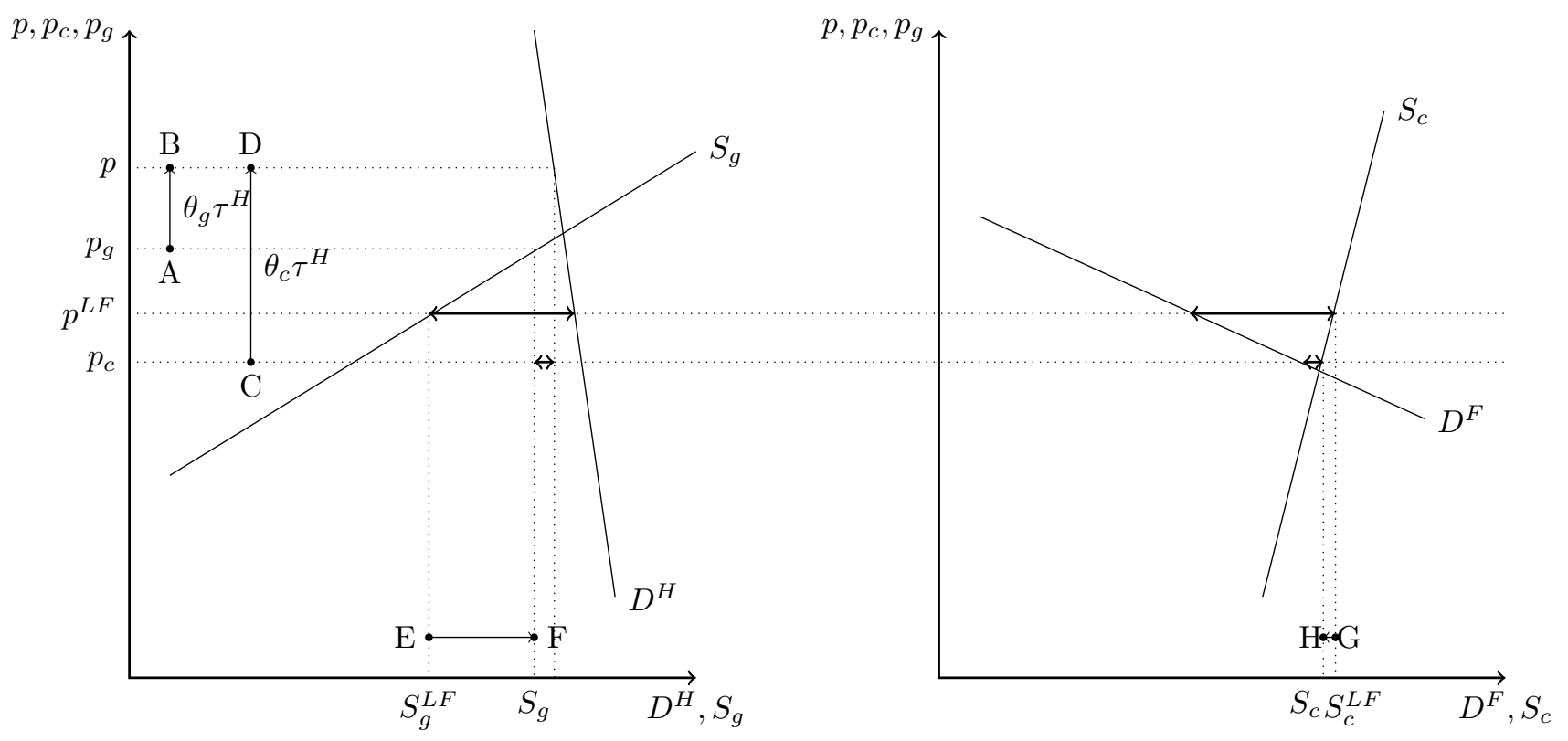

Figure 3: Increased total emissions $e^{W}$

$|A B| /|C D|=\theta_{g} / \theta_{g}>\Delta S_{c} / \Delta S_{g}=|G H| /|E F|$ implies $\Delta e^{W}=\theta_{c} \Delta S_{c}+\theta_{g} \Delta S_{g}>0$

coal production is less pronounced and the potential gas rise is more pronounced, making it more likely that CO2 emissions increase worldwide. Lemma 4 further shows a less elastic coal supply is associated with a higher CO2 leakage rate, despite the fact that it induces a less pronounced potential increase in gas production. Indeed, for example, with a perfectly elastic coal supply, the domestic CO2 reduction policy would destroy domestic coal production and exports, whereas, with an elastic coal supply it induces some coal use to be displaced from the Home economy to the rest of the world.

The polar case in which $r=0$ corresponds to the situation in which coal and gas are equally polluting, as in a standard model with a homogeneously polluting carbon energy source and a less-than-100\% leakage. Therefore, the last result of Lemma 4 shows that leakage is systematically increased by the presence of gas as a cleaner energy source. In other words, the possibility that, in our model, the domestic unilateral CO2 reduction policy be counterproductive - already suggested, and illustrated in Figure 3-arises from the multiplicity of carbon energy sources with different CO2 intensity.

Appendix A shows that the leakage rate (9) is more than $100 \%$ if and only if the 
following polynomial function of $r$ takes a positive value: ${ }^{25}$

$-r^{2} S_{c} \xi_{S_{c}}\left(D^{H} \xi_{D^{H}}+S_{g} \xi_{S_{g}}\right)+r\left(S_{g} \xi_{S_{g}} D^{F} \xi_{D^{F}}-2 D^{H} \xi_{D^{H}} S_{c} \xi_{S_{c}}\right)-D^{H} \xi_{D^{H}}\left(S_{c} \xi_{S_{c}}+S_{g} \xi_{S_{g}}\right)>0$.

Analysis of this inequality shows the following conditions under which the unilateral CO2 reduction policy is effective or not at reducing world $\mathrm{CO} 2$ emissions - see the proof in Appendix A.

\section{Proposition 3 (Policy ineffectiveness)}

1. The domestic CO2 reduction policy may increase world emissions ( $d e^{W} / d \tau^{H}>0$ ) only if

$$
\frac{S_{g} \xi_{S_{g}}\left(D^{F} \xi_{D^{F}}\right)^{2}}{D^{H} \xi_{D^{H}} S_{c} \xi_{S_{c}}}>D^{H} \xi_{D^{H}}+D^{F} \xi_{D^{F}}+S_{c} \xi_{S_{c}}+S_{g} \xi_{S_{g}}
$$

i.e., otherwise world CO2 emissions are always reduced;

2. Condition (11) may only be satisfied when (7) is satisfied, i.e., when $d S_{g} / d \tau^{H}>0$;

3. Moreover, it is more likely to be satisfied when $\xi_{D^{H}}$ and $\xi_{S_{c}}$ are sufficiently low, and $\xi_{S_{g}}$ and $\xi_{D^{F}}$ are sufficiently high;

4. When condition (11) is satisfied, there exist thresholds $\underline{r}$ and $\bar{r}$ defined in Appendix A, with $r_{0}<\underline{r}<\bar{r}$, such that the domestic policy induces an increase in world emissions $d e^{W} / d \tau^{H}>0$-i.e., a more-than-100\% leakage-if and only if

$$
\underline{r}<r<\bar{r} .
$$

The first point of Proposition 3 provides a necessary condition under which the unilateral domestic $\mathrm{CO} 2$ reduction policy is counterproductive. It has two implications expressed in the second and third points of the proposition.

First, world emissions may only increase when the domestic CO2 reduction policy increases gas production. This immediately follows from previous results. Indeed, consider expression (8) of world CO2 emissions: Since coal use systematically decreases, world

\footnotetext{
${ }^{25}$ As Appendix A makes clear, derivatives in the coefficients of the polynomial function-denoted $P(r)$ in the appendix - do not depend on pollution parameters $\theta_{c}$ and $\theta_{g}$ contained in the variable $r$ since our analysis focuses on a marginal policy variation in a neighborhood of the laissez-faire equilibrium in which $\tau^{H}=0$.
} 
emissions may only increase if gas production is increased. Otherwise, the production of both energy sources is depressed as in the leakage analysis with a single carbon source in which the leakage rate is always less than $100 \%$.

Second, the role of demand and supply elasticities in the third point of the proposition is similar to their role already identified by Lemma 4. Indeed world emissions are more likely to increase as the factors augmenting the leakage rate are stronger - see the comments following Lemma 4.

The last point of the proposition further provides a condition for the ineffectiveness of the domestic CO2 reduction policy which focuses on the role of coal and gas pollution intensities. Assuming that the necessary condition (11) holds, it tells that the unilateral $\mathrm{CO} 2$ reduction policy is counterproductive for intermediate values of the degree of gas' cleanliness $r$.

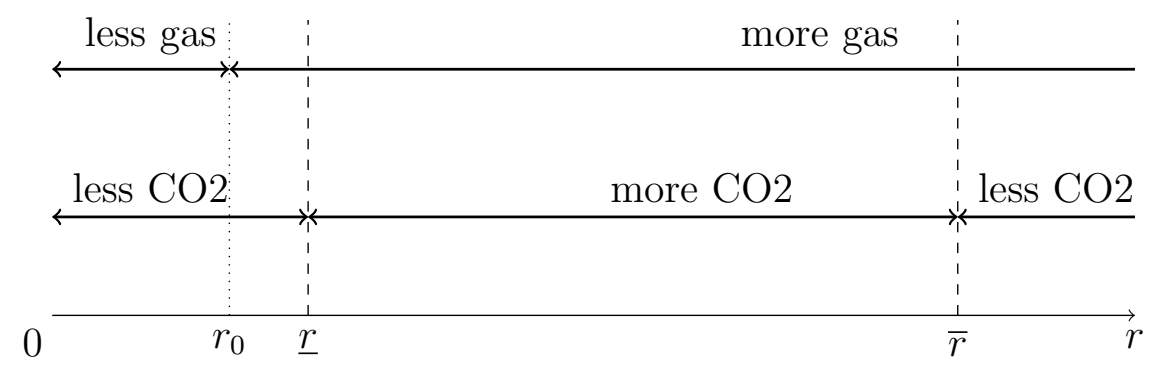

Figure 4: Gas' cleanliness and changes in gas production and in world CO2 emissions

The resulting possible scenarios are illustrated in Figure 4, which can be explained as follows. Note first that, by Proposition 2, if gas is relatively dirty $\left(r \leq r_{0}\right)$, then gas production is reduced along with coal production as a result of the policy, implying that world emissions do not increase. Otherwise, when $r>r_{0}$, the change in world $\mathrm{CO} 2$ emissions become ambiguous (second point of Proposition 3). In this context, the degree of gas' cleanliness $r$ has two effects of opposite directions.

Consider an increase in $r$ above the threshold level $r_{0}$; for example, this may result from a decrease in $\theta_{g}$, holding $\theta_{c}$ unchanged. On the one hand, as $r$ increases and gas becomes cleaner, the unilateral policy implies a more pronounced rise in gas production (Lemma 3) and a more pronounced decrease in coal production (Lemma 2), which respectively contribute to increase and decrease CO2 emissions. This effect may be called a quantity effect of gas' cleanliness. On the other hand, as $r$ increases, a given increase in 
gas production contributes relatively less to increasing total $\mathrm{CO} 2$ emissions. This effect is about the impact of quantity changes on emissions. This twofold effect of gas' relative cleanliness explains the fact that the policy-induced rise in gas production does not cause world emissions to increase, but for intermediate degrees of gas' cleanliness. For example, consider two polar cases. When $r=r_{0}$, the unilateral policy does not induce gas to increase at all, hence it does not contribute to increase world emissions. When $r$ tends to be infinite - and gas tends to be carbon free - the policy induces gas to increase a lot, but this does not affect emissions either.

The various possibilities identified in Proposition 3 depend on whether conditions (11) and (12) are satisfied. These testable conditions do not only involve the rate of gas' cleanliness $r=\left(\theta_{c}-\theta_{g}\right) / \theta_{g}$, but also reflect the observed equilibrium characteristics of the gas-rich Home country implementing the unilateral CO2 reduction policy. This motivates, for example, the application of Section IV to the case of the US.

In the context of the rise of gas in the US, the replacement of domestic coal use, and the concomitant increase in US coal exports, our analysis shows that several aspects raise concerns about the effectiveness of the US CO2 reduction. First, according to Newell, Prest, and Vissing (2019), the price responsiveness of shale gas production is three times larger than that of conventional forms of gas. Therefore, the possibility that a unilateral $\mathrm{CO} 2$ reduction policy relying on gas be counterproductive is even more concerning as gas is produced from shale resources. Moreover, the unilateral policy is also more likely to be counterproductive as the foreign demand for coal is more elastic. For example, Burke and Liao (2015) suggest that the demand for coal has become significantly more elastic in China.

\section{F. Foreign CO2 Commitment and Policy Implementation}

We have hitherto examined the domestic CO2 reduction policy under the assumption that the rest of the world does not implement any policy. In that case, we have established the conditions under which the domestic policy increases excessively the emissions of the Foreign country so that it may become counterproductive at the world level. In fact, in the aftermath of the Paris agreement, it is also interesting to examine the case in which the rest of the world is committed to limit its CO2 emissions. That is what we do in 
this subsection: We assume that the Foreign country's CO2 emissions are limited to the exogenous level $\bar{e}^{F}$. With our simplifying assumption that the Foreign country only relies on the coal energy, that means

$$
\theta_{c} D_{c}^{F}=\bar{e}^{F}
$$

Consider that this limitation is implemented by means of a carbon fee $\tau^{F}>0$, like in the Home country. It implies a carbon penalty $\theta_{c} \tau^{F}$ on the Foreign country's use of coal. Accordingly, the coal consumer price in the rest of the world should be adjusted to become, instead of $p_{c}=p-\theta_{c} \tau^{H}$ as per equation (4),

$$
p_{c}=p-\theta_{c} \tau^{H}+\theta_{c} \tau^{F}
$$

where, following our previous formulation, $p-\theta_{c} \tau^{H}$ remains the international price of the coal energy. Consequently, the world energy balance condition (5) should be adjusted to become

$$
D^{H}(p)+D^{F}\left(p-\theta_{c} \tau^{H}+\theta_{c} \tau^{F}\right)=S_{c}\left(p-\theta_{c} \tau^{H}\right)+S_{g}\left(p-\theta_{g} \tau^{H}\right)
$$

In the context of this subsection, compared with the previous setting in the absence of policy in the rest of the world, equilibrium prices $p$ and $\tau^{F}$ are determined so as to satisfy the new world energy market equilibrium condition (15) as well as the new Foreign country's commitment

$$
\theta_{c} D^{F}\left(p-\theta_{c} \tau^{H}+\theta_{c} \tau^{F}\right)=\bar{e}^{F}
$$

In this new setting, Appendix A shows that the domestic CO2 reduction policy still induces a lower coal price $p_{c}$ and more coal exports $S_{c}^{H}-\left(D^{H}-S_{g}\right)$ from the Home country to the rest of the world. Although, by assumption, CO2 emissions in the latter are not increased, the carbon equilibrium penalty $\tau^{F}$ needs to increase to ensure that the cap (13) is satisfied: It means that the domestic CO2 reduction policy makes it more difficult for the rest of the world to meet its own commitment.

The following proposition-proved in Appendix A - establishes the extent to which the carbon price in the rest of the world must increase in response to the domestic CO2 reduction policy so that the emission limit $\bar{e}^{F}$ is not exceeded.

Proposition 4 (Policy in the rest of the world) When the Foreign country is committed to a set amount of CO2 emissions, the domestic CO2 reduction policy requires 
that the carbon fee in the Foreign country raises by

$$
\frac{d \tau^{F}}{d \tau^{H}}=\frac{D^{H} \xi_{D^{H}}+r S_{g} \xi_{S_{g}}}{D^{H} \xi_{D^{H}}+S_{c} \xi_{S_{c}}+S_{g} \xi_{S_{g}}}>0
$$

this adjustment is larger when the rate $r$ is higher and $\xi_{S_{c}}$ is lower.

The role of the elasticity of coal supply is intuitive since a lower $\xi_{S_{c}}$ increases the leakage rate as per Lemma 4. Moreover, interestingly, expression (17) also shows that the relative rise in the rest of the world's carbon price is more pronounced as the rate of gas' cleanliness $r$ is higher, all other things being equal. This suggests that, in reaction to the domestic $\mathrm{CO} 2$ reduction policy, the rest of the world should increase its carbon penalty even more when gas is less CO2 intensive relative to coal.

\section{Numerical Application to the US}

We have already stressed the relevance of the US example by documenting the following developments: The US administration's past commitment to reduce the country's CO2 emissions, and the effective reduction in the US CO2 emissions, have gone hand in hand with the rise in the production of gas and its substitution for coal in the US power sector; moreover, this replacement has been concomitant with an increase in the US exports of coal. The predictions of our model are in line with these developments, indicating the relevance of our theory for the case of the US.

In this section, we illustrate the theoretical results of Section III by applying them to the case of the US. The stylized nature of our model can only provide a limited approximation of the actual policy relevance and effectiveness of the coal-gas substitution occurring in the US. Accordingly, our application should not be used to draw definitive policy lessons.

That being said, it is of interest to evaluate our results with empirically-estimated values of the parameters. Besides an approximative estimation of the effectiveness of the US climate policy project to reduce its $\mathrm{CO} 2$ emissions by relying on the rise of gas, our application provides an illustration of our results that highlights the potentially critical role of some parameters.

We will use the following sensible approximations of market shares, as well as empirical estimates collected from the existing literature on energy demand and supply elasticities. 


\section{A. Empirical Estimates of Parameters and Equilibrium Values}

Coal and gas relative CO2 intensity. Following the Intergovernmental Panel on Climate Change (IPCC, 2014, Annex 3, Table A.3.2), the relative CO2 pollution intensity of coal is approximately $\theta_{c} / \theta_{g}=2$, implying that the rate in pollution increase from gas to coal defined in (6) is $r=1$.

Although the use of this ratio is standard, it is also controversial for one main reason already mentioned in the introduction: Gas contributes to climate change not only by releasing $\mathrm{CO} 2$ when burnt but also by potentially releasing methane when extracted. According to Howarth et al. (2011), if methane emissions generated by the production of gas were not avoided, coal and gas would have similar climate impacts over a century. This possibility is captured by the value of $r=0$. This extreme value also corresponds to the assumption made in models that consider a single, representative carbon source of energy.

Market shares. Data from the US Energy Information Administration (EIA) ${ }^{26}$ and BP (2019) suggest the following approximation: Were the current world production/consumption of coal and the US gas production/consumption normalized to 11 units of energy in 2018, its production would be decomposed as $S_{c}=10$ units of coal production and $S_{g}=1$ unit of US gas production. On the consumption side, $D^{H}=2$ units of energy would be consumed in the US, and $D^{F}=9$ units of the 10 units of world coal production would be consumed in the rest of the world. Accordingly, the 2 units of US energy consumption would consist of about $D_{c}^{H}=1$ unit of coal consumption and 1 unit of gas consumption.

US electricity demand price elasticity. Various studies estimate the price elasticity of the demand for electricity in the US residential, commercial and industrial sectors: Maddala et al. (1997), Garcia-Cerrutti (2000), Bernstein and Griffin (2006), Paul et al. (2009), and Deryugina et al. (2020). They find consistent estimates across sectors and over time, ranging from 0.1 in the short run to 0.4 in the long run. ${ }^{27}$

\footnotetext{
${ }^{26}$ The data used here are available at https://www.eia.gov/electricity/data.php and https: //www.eia.gov/outlooks/ieo/.

${ }^{27}$ In our model, price elasticities are medium-run responses, i.e., evaluated over periods of time that allow the replacement of coal-fired power stations by gas-fired ones. In reality, the elasticity of the demand for coal and gas induced by the demand for the electricity produced from these energy sources may differ from the elasticity of the final electricity demand because there are other, alternative ways of producing electricity. However, alternative sources currently play a minor role in electricity generation.
} 
Therefore, our numerical application will assume the intermediate value of 0.2 for the price elasticity $\xi_{D^{H}}$ of the US demand of coal and gas for electricity generation purposes. Non-US coal demand price elasticity. The non-US demand for coal-especially in the top coal-consuming Chinese economy - is often considered to be very inelastic in the short run. This assumption has recently been questioned by Burke and Liao (2015). They estimate the price elasticity of the demand for coal over the 1998-2012 period. They find a range 0.3 to 0.7 when responses are considered over a two years period of time. ${ }^{28}$

Accordingly, our numerical application will assume the middle-of-the-road value of 0.5 for the price elasticity $\xi_{D^{F}}$ of the demand for coal in the rest of the world.

Coal and gas supply price elasticity. The price elasticity of fossil fuels' supply is usually low, even in the long run; it reflects the scarcity of economically exploitable resources.

As far as natural gas is concerned, Dahl's (2009) and Brown and Krupnick's (2010) estimates of the medium- to long-run price elasticity of supply range from 0.4 to 1.4 . Accordingly, our numerical application will assume a baseline value of 1 for $\xi_{S_{g}}$. Moreover, Newell et al. (2019) point out that the production of the US shale gas resource is three times as responsive as conventional gas. It is, therefore, sensible to extend the range of admissible gas supply elasticity estimates to the extreme value of 4.2.

The empirical literature on the price elasticity of coal supply - e.g., Labys et al. (1979), Beck et al. (1991), Light (1999), Light et al. (1999), and Dahl (2009)-finds estimates ranging from 0.1 and $1.9 .^{29}$

In our numerical application, in light of this literature, we assume the baseline value of 1 for the price elasticity of coal supply $\xi_{S_{c}}$.

Table 1 summarizes the baseline values of parameters for our numerical application. It also indicates intervals of reasonable values for elasticity parameters and for the degree of gas' cleanliness that we will consider in our sensitivity analysis. These intervals show that supply elasticity estimates are characterized by a greater dispersion than their demand

\footnotetext{
${ }^{28}$ These results are comparable to Truby and Paulus' (2012) short-run estimate of 0.4 for the coal demand elasticity in Europe in 2008. For their simulation, Chakravorty et al. (2015) assume a price elasticity of the energy demand of 0.4 for the industrial sector and of 0.5 for the commercial and residential sectors.

${ }^{29}$ Dahl and Duggan (1996) report the existence of some extreme estimates from virtually 0 to not less than 7.9. We do not consider such a large range of values and focus, instead, on the more consistent $0.1-1.9$ set of estimates.
} 
counterparts. Accordingly, our sensitivity analysis will mainly focus on the former.

\begin{tabular}{ccccccccc}
$r$ & $S_{c}$ & $D^{H}$ & $S_{g}$ & $D^{F}$ & $\xi_{D^{H}}$ & $\xi_{D^{F}}$ & $\xi_{S_{c}}$ & $\xi_{S_{g}}$ \\
\hline 1 & 10 & 2 & 1 & 9 & 0.2 & 0.5 & 1 & 1 \\
{$[0,1]$} & - & - & - & - & {$[0.1,0.4]$} & {$[0.3,0.7]$} & {$[0.1,1.9]$} & {$[0.4,4.2]$} \\
\hline
\end{tabular}

Table 1: Baseline parameters' values and reasonable intervals

\section{B. Results of the Application and Sensitivity Analyses}

CO2 reduction policy in the US and domestic gas production. According to Proposition 2, condition (7) tells whether the Home country CO2 reduction policy causes a rise in gas production. In the case of the US, the values given in Table 1 yield $r_{0}=0.03$ for the right-hand-side threshold of condition (7), which largely falls short of the value of 1 for the rate of pollution increase $r$. This application of Proposition 2, therefore, suggests that a reduction of CO2 emissions in the US should imply that US production of gas increases.

CO2 reduction policy in the US and world CO2 emissions. Proposition 3 and its analysis tell us that a rise in domestic gas production induced by a unilateral reduction of CO2 emissions may be accompanied by a more-than-100\% leakage rate causing an ultimate increase in world $\mathrm{CO} 2$ emissions.

In the case of the US, however, the baseline values chosen above imply that (11) is not satisfied, implying that a US CO2 reduction reached by means of a domestic rise in gas does not induce world CO2 emissions to increase, irrespective of the degree $r$ of gas' cleanliness. Accordingly, the associated leakage rate as expressed in (9) takes the value of

$$
\frac{\frac{d e^{F}}{d \tau^{H}}}{-\frac{d e^{H}}{d \tau^{H}}}=42.5 \% .
$$

This number, although relatively high, significantly falls short of the $100 \%$ countereffectiveness threshold. This, nevertheless, happens to change when other values of supply and demand elasticities are considered.

Variations in supply price elasticities. Given the variety of empirical estimates of the coal and gas supply elasticities, it seems important to examine how our results vary with these parameters. As far as gas is concerned, all combinations of elasticity parameter 
values within the ranges given in Table 1 imply that a reduction of $\mathrm{CO} 2$ emissions in the US should increase US gas production.

However, the leakage rate of $42.5 \%$ just obtained is sensitive to changes in $\xi_{S_{c}}$ and $\xi_{S_{g}}$. This is illustrated by the iso-leakage-rate curves of Figure 5 in the gas- and coalsupply elasticities' space over the intervals of reasonable values for these parameters, other parametric values being held unchanged at their baseline level.

First, these curves illustrate a result of Lemma 4: They reflect that the leakage rate becomes higher as the elasticity of gas supply increases and as the elasticity of coal supply decreases, making the US CO2 reduction policy more likely to be counterproductive. This is especially concerning since the US shale gas resource exhibits a particularly high supply elasticity (Newell et al., 2019). In particular, Figure 5 shows that the leakage rate may exceed $100 \%$ for elasticity values that fall into the range of admissible values given in Table 1, as, for example, with $\xi_{S_{c}}=0.2$ and $\xi_{S_{g}}=2$.

Second, however, the slope of the iso-leakage-rate curves indicates that it is the coal supply elasticity that plays the most crucial role. This calls for more consistent empirical estimates of this elasticity in the current energy landscape.

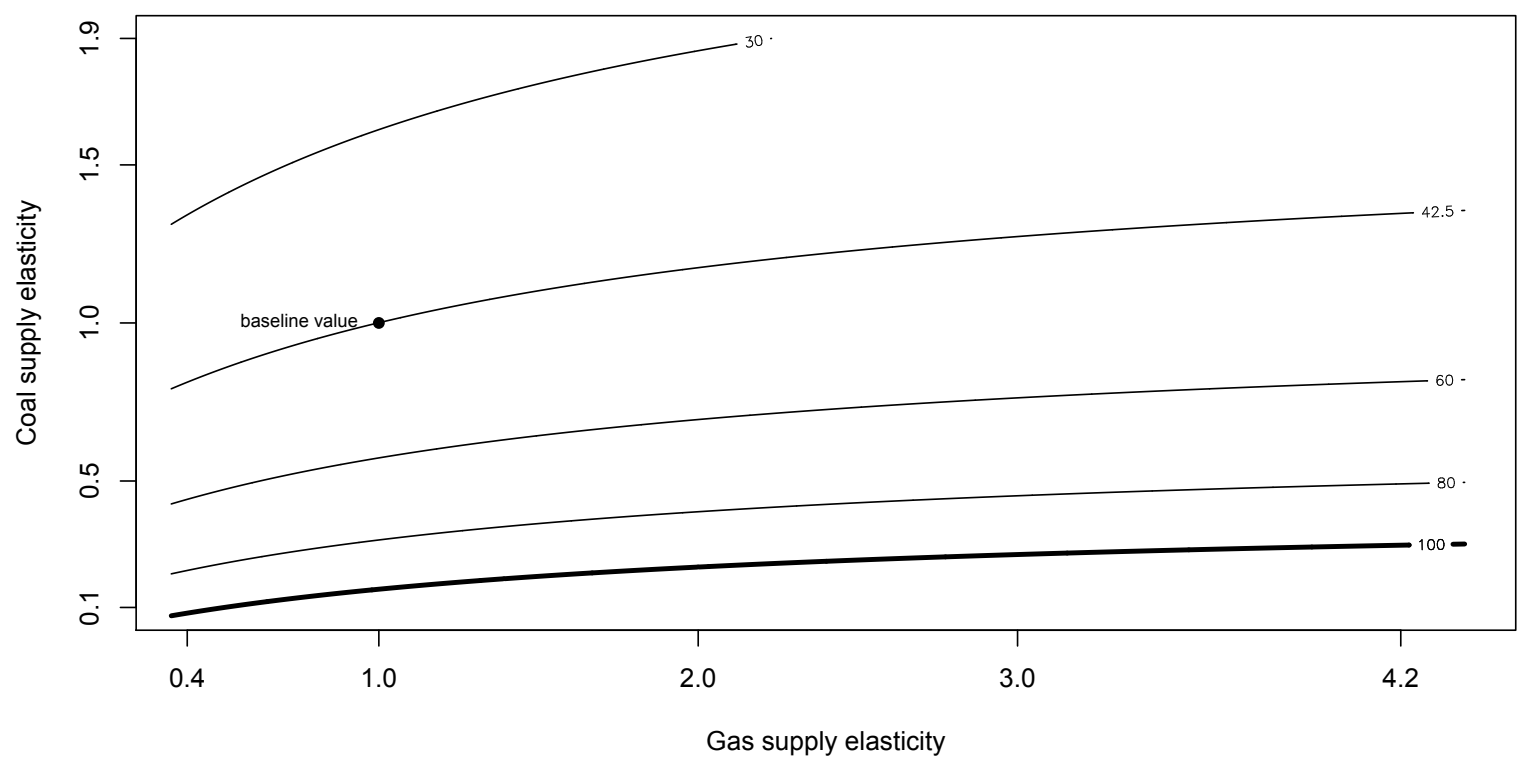

Figure 5: Curves of iso-leakage-rate and supply elasticities

Variations in relative domestic and foreign energy demand elasticities. The 
obtained leakage rate of $42.5 \%$ is also sensitive to changes in the price elasticities $\xi_{D^{H}}$ and $\xi_{D^{F}}$ of the US demand for energy and foreign demand for coal, although this sensitivity is less significant than with respect to supply elasticities.

This is illustrated in Appendix B by the iso-leakage-rate curves of Figure 7 in the foreign- and US-demand elasticities' space over the reasonable range of elasticity values, other parametric values being held unchanged at their baseline level. Like supply elasticities, these curves show that the leakage rate becomes larger as the elasticity of the foreign demand for coal increases and as the elasticity of the US demand for energy decreasesan illustration of Lemma 4's results. Moreover, the figure suggests that the non-US coal demand elasticity plays the most crucial role. The high sensitivity of the leakage rate to the rest-of-the-world's energy demand elasticity is concerning because this elasticity may have significantly increased in recent years, as Burke and Liao (2015) suggest in the case of China.

Variations in relative CO2 intensities. According to our baseline application of Proposition 2, a reduction of CO2 emissions in the US should only decrease gas production if gas were virtually as polluting as coal $(r<0.03)$.

Similarly, Figure 6 shows that changes in the degree of gas' cleanliness $r$ in the neighborhood below the standard value of 1 does not modify significantly the rate of leakage. For example, the leakage rate is maximum at $43.6 \%$ when coal is $60 \%$ more polluting than gas.

Were gas as polluting as coal $(r=0)$, however, the leakage rate would fall to $29 \%$, rather than $42.5 \%$ under the standard value $r=1$. This illustrates the result of Lemma 4 that the leakage rate is higher when gas is a cleaner energy source. It shows, moreover, that the often-made simplifying assumption of a single homogeneously polluting energy source may lead to importantly underestimate the leakage rate.

CO2 reduction policy in the US and policy in the rest of the world. According to Proposition 4, formula (17) indicates the relative increase in the carbon price that the rest of the world must implement to ensure that its CO2 commitment remains satisfied in the face of the domestic CO2 reduction. With our baseline values, the application of this formula tells us that, following a given rise in the US price of carbon, the rest of the world should react by raising its carbon price by $12 \%$ of the carbon price rise in the US. 


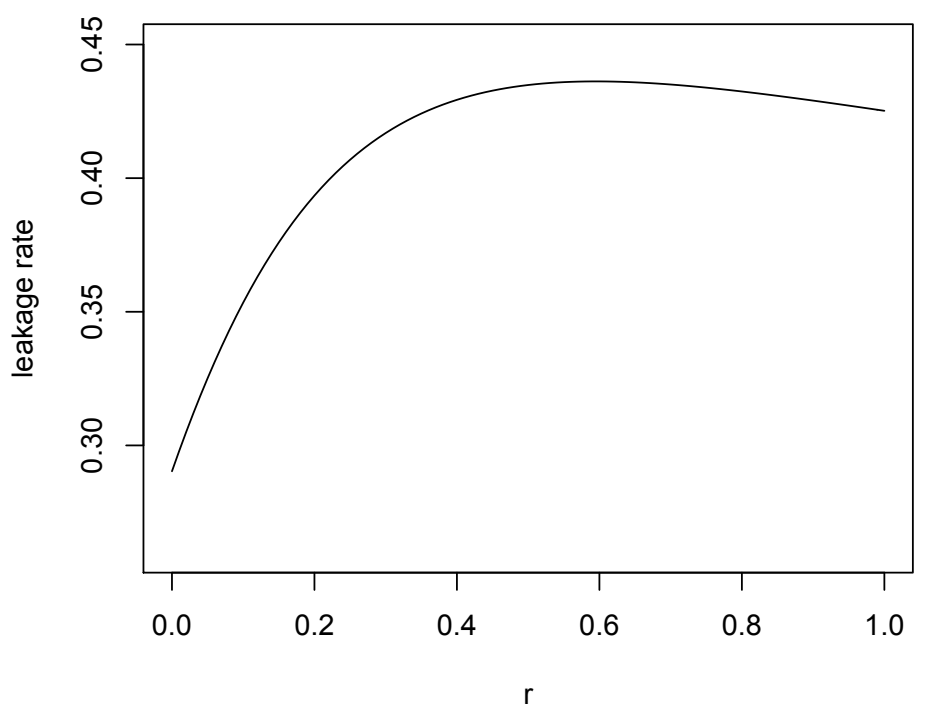

Figure 6: Leakage rate and the rate of increase of pollution from gas to coal

With a single resource $(r=0)$ - as when the presence of gas as a cleaner energy source is ignored - the rise in rest-of-the-world carbon price should be of only $3.5 \%$.

\section{Extensions of the Model}

The stylized nature of our model is a methodological and pedagogical choice of focusing on the most fundamental aspects of our theory: an open-economy relying on carbongenerating coal and gas, using its gas domestically and trading coal with the rest of the world. Consequently, our results have been obtained under simplifying conditions and one may question whether these results survive extensions to more complex settings. Six main aspects are omitted in our analysis, which deserve further discussion. For the sake of clarity, we discuss each of them in isolation.

\section{A. Dynamic Coal and Gas Supplies}

Our analysis may be extended to dynamic coal and gas supply in the following standard and straightforward manner. Assume that both energy sources are costlessly produced over some time horizon by Hotelling-style (Hotelling, 1931) competitive sectors seeking to maximize long-term profits. Moreover, consider that these sectors develop exploitable reserves prior to extracting them at some convex exploration and development costs, in 
the fashion first proposed by Gaudet and Lasserre (1988). Under these assumptions, as is widely known in the field of nonrenewable-resource economics, the formulation of the model in terms of cumulative quantities over the time horizon is isomorphic to the static model of Sections II and III; it follows that the analysis of a unilateral CO2 reduction policy on total emissions yields the same results as Propositions 1-4. The formulas only differ by the notion of supply elasticities involved, which emerge as elasticities of the longrun production of reserves, rather than static supply elasticities; this difference highlights that the elasticity notion that is relevant for our analysis should reflect sufficiently longrun supply responses.

\section{B. International Gas Trade and Transportation Costs}

The second aspect that needs to be discussed is the possibility that natural gas be traded. As already mentioned in the introduction, the international trade of gas is highly challenging in comparison with coal. However, despite this difference, the former is progressively becoming reality. ${ }^{30}$

Appendix C presents a basic extension of our model that features quadratic transportation costs and allows not only exports of domestic coal, but also exports of domestic gas. We provide a condition under which there is a unique interior equilibrium in which both coal and gas are exported from the home economy to the rest of the world in strictly positive quantities.

Moreover, in the spirit of the paper's main analysis, Appendix C establishes conditions under which the domestic $\mathrm{CO} 2$ reduction policy causes more gas to be produced and under which this contributes to increase CO2 emissions worldwide. Analysis of this extension is tedious and goes beyond the scope of this paper. However, the appendix makes clear that the unilateral CO2 reduction policy may entail a more-than- $100 \%$ leakage rate even when both coal and gas are exported.

\section{Gas Supply in the Rest of the World}

As a matter of fact, natural gas is produced in various gas-rich regions. That being said, as already mentioned in the introduction and reminded in the previous subsection,

\footnotetext{
${ }^{30}$ For example, following a wave of investments in Liquefied Natural Gas export terminals, the US has shipped natural gas since February 2017.
} 
regional gas markets are hardly integrated, despite the fact that the international trade of gas is progressively becoming reality - see, e.g., Li, Joyeux, and Ripple (2014), and Arezki et al. (2017).

The extension of our theory to the presence of non-internationally-tradable gas, not only in the domestic economy, but also in the rest of the world, has an obvious implication: As the domestic CO2 reduction policy negatively impacts the international price of coal, it induces a reduction in foreign gas production. This effect mitigates the carbon leakage and, therefore, the potential rise of $\mathrm{CO} 2$ emissions at the world level.

Appendix D formally examines this extension of our model. Besides the quantitative adjustment just explained, the analysis follows the same steps as the main text with similar qualitative conclusions, including the possibility of more-than- $100 \%$ leakage.

\section{Additional Non-Tradable Non-Carbon Energy Sources}

As already explained in the main text, the extension of the model to the case in which other non-tradable non-carbon energy sources can be used to produce electricity is straightforward once energy demand functions are reinterpreted as residual demands after other energy sources have been used. Therefore, the extension of our model to the presence of such alternative energy sources does not imply any qualitative nor quantitative adjustments.

\section{E. Technical Progress in the Production of Gas, and Development of Non-Carbon Energy Sources}

Technological changes in energy production are factors which, although theoretically orthogonal to the policy under study in this paper, may play an important role in practice. As a complement to the main text's analysis, Appendix E examines technical improvements in the technology of domestic gas production and the deployment of alternative non-carbon energy sources. The former amounts to a positive shift in the domestic gas supply function; the latter, in light of the previous subsection, can be characterized by a negative shift in the (domestic and foreign) demand for carbon energy sources.

As a complement to the main text's analysis of changes in the domestic CO2 emissions' governmental commitment, Appendix E examines the effect of shifting both the domestic gas supply and the demand for carbon energy sources. For simplicity, the appendix 
focuses on these changes and, therefore, assumes away CO2 reduction policies. It shows that technical improvements in the production of gas affect world CO2 emissions in a way comparable with a domestic CO2 reduction policy relying on the replacement of coal by gas. ${ }^{31}$ The analysis of the appendix further shows that the development of noncarbon energy production systematically contributes to the reduction of $\mathrm{CO} 2$ emissions worldwide. The policy promotion of non-carbon energy sources is, clearly, a way of reducing world CO2 emissions that is less hazardous than the unilateral promotion of the gas energy source.

\section{F. Imperfect Substitutability between Carbon Energy Sources}

The model of Sections II and III considers that coal and gas energy sources are perfectly substitutable in the production of final energy. As already mentioned, this assumption is sensible for the power sector in a sufficiently long-term perspective.

In other contexts, however, this assumption is less compelling. For example, for other uses than electricity production, coal and gas may not be substitutable at all. To deal with such situations, one possibility is to follow Hoel (1984) who suggests to retain the assumption of perfect substitutability for some segments only and to further consider uses that are specific to each energy source. Intuitively, such an extension would not qualitatively modify our results.

Another possibility - which is often used in CGE models to reflect substitution difficulties at the economy level - is to consider an aggregate production function in which energy inputs are related by a constant elasticity of substitution. In Appendix F, we show how our analysis accommodates a CES electricity production function of the coal and gas inputs. Although the analysis is tedious, it yields conditions that resemble those of Propositions 2 and 3 except that they involve the elasticity of substitution parameter. In particular, the result that the possibility that the leakage rate induced by the unilateral CO2 reduction policy exceeds $100 \%$ carries over. The appendix further verifies that the formulas converge to their counterparts in the main text when coal and gas tend to be perfectly substitutable.

\footnotetext{
${ }^{31}$ In particular, this result of Appendix E substantiates the claim of footnote 23 regarding the impact of an exogenous increase in domestic gas production on domestic CO2 emissions.
} 


\section{Conclusion}

Our analysis stresses that the presence of a cleaner carbon energy source like gas augments the leakage rate that results from a unilateral $\mathrm{CO} 2$ reduction policy relative to situations in which energy sources are homogenously polluting and, therefore, equally penalized. As a result, with such a cleaner energy source, a well-intentioned unilateral CO2 reduction policy may be more than offset by a more-than-100\% leakage rate, making the policy counterproductive at the world level. This sharply contrasts with the standard analysis of unilateral policies with a single, representative carbon energy source, in which the leakage rate is always less than $100 \%$. Therefore, an examination was needed of the circumstances under which a unilateral policy relying on gas turns counterproductive. We have established simple and testable conditions ( $($ ) under which a domestic CO2 reduction implies that gas production should increase and $(\imath)$ under which such an increase effectively reduces CO2 emissions at the world level.

Our results look simple. However, they are new and they shed light on a currently important policy option. Indeed, in the aftermath of the Paris Climate Agreement, countries will rely on unilateral initiatives to meet their $\mathrm{CO} 2$ reduction targets. In this context, a number of large gas-rich economies hope to do so by increasing their gas production, whereas, at the same time, others increasingly rely on coal.

Our formulas can be applied to any gas-rich region to approximately evaluate whether the option of relying on gas effectively contributes to reducing $\mathrm{CO} 2$ emissions at the world level. For example, our application to the most important US case with sensible empirical estimates suggests that the rise of gas in the US might not only be justified by the reduction of national CO2 emissions, but also by the need to reduce CO2 emissions at the world level. This application is illustrative; evaluating the effectiveness of unilateral gas-based $\mathrm{CO} 2$ reduction policies in other gas-rich regions goes beyond the objective of this paper.

Our model is too stylized to draw definitive policy conclusions. However, our theory indicates that, in the presence of more than one carbon energy source, the sensitivity of energy demand in the domestic economy and the rest of the world as well as the sensitivity of energy supplies are in general critical to the effectiveness of unilateral CO2 reduction 
initiatives. More precisely, an open economy's CO2 reduction based on the rise of gas and its substitution for coal may be counterproductive at the global level as soon as its energy demand and coal supply are not sufficiently price elastic, energy demand in the rest of the world and the domestic supply of gas are not sufficiently inelastic, and gas is relatively cleaner than coal but not sufficiently so.

Accordingly, our analysis calls for examining more carefully the global impact of relying on gas to reduce domestic emissions, not only in the US but also wherever this is a relevant policy option. Moreover, our application calls for more empirical research on the estimation of coal and gas supply and demand elasticities.

Finally, an important caveat to our analysis is that it focuses on policies that penalize CO2 emissions generated by the domestic use of carbon energy sources, under the rationale that this is consistent with most unilateral policy commitments and initiatives. In this context, our analysis highlights that these policies may boost not only the production of a cleaner carbon energy source like gas but also exports of the most polluting energy sources, increasing leakage to a potentially dangerous extent. Clearly, this raises the question whether unilateral policies including carbon energy exports - see, e.g., Metcalf's (2009) proposal - or policies simply targeting the domestic production of carbon sources would be more effective. This question goes beyond the scope of this paper and would certainly deserve more attention in future research. 


\section{REFERENCES}

Arezki R., T. Fetzer, and F. Pisch (2017), "On the Comparative Advantage of US Manufacturing: Evidence from The Shale Gas Revolution," Journal of International Economics, 107: 34-59.

Babiker, M.H. (2005), "Climate Change Policy, Market Structure, and Carbon Leakage," Journal of International Economics, 65: 421-445.

Baylis, K., D. Fullerton, and D.H. Karney (2014), "Negative Leakage," Journal of the Association of Environmental and Resource Economists, 1: 51-73.

Beck, T., L. Jolly, and T. Loncar (1991), "Supply Response in the Australian Black Coal Industry," Australian Bureau of Agricultural and Resource Economics Technical Papers, 91.1.

Bernstein, M.A., and J. Griffin (2006), "Regional Differences in the Price-Elasticity of Demand for Energy," RAND Technical Reports, 292.

BP (2019), BP Statistical Review of World Energy 2019.

Brown, S.P., and A. Krupnick (2010), "Abundant Shale Gas Resources: Long-Term Implications for US Natural Gas Markets," RFF Discussion Papers, 10-41.

Burke, P.J., and H. Liao (2015), "Is the Price Elasticity of Demand for Coal in China Increasing?," China Economic Review, 36: 309-322.

Burniaux, J.-M., and J. Oliveira Martins (2012), "Carbon Leakages: A General Equilibrium View," Economic Theory, 49: 473-495.

Burtraw D., C. Fischer, C. Munnings, K.L. Palmer, A. Paul, N. Richardson, J.-S. Shih, and R.C. Williams III (2014), "Comments to the US Environmental Protection Agency on Its Proposed Clean Power Plan," RFF Report.

Chakravorty, U., C. Fisher, and M.-H. Hubert (2015), "Will Shale Gas Reduce Carbon Emissions From China?," mimeo, Tuft University.

Château, J., R. Dellink, and E. Lanzi (2014), "An Overview of the OECD ENV-Linkages Model: Version 3," OECD Environment Working Papers, 65.

Chakravorty, U., M. Moreaux, and M. Tidball (2008), "Ordering the Extraction of Polluting Nonrenewable Resources," American Economic Review, 98: 1128-1144.

Coulomb, R., and F. Henriet (2017), "The Grey Paradox: How Oil Owners can Benefit from Carbon Regulation," Journal of Environmental Economics and Management, forthcoming.

Cullen, J.A., and E.T. Mansur (2017), "Inferring Carbon Abatement Costs in Electricity Markets: A Revealed Preference Approach using the Shale Revolution," American Economic Journal: Economic Policy, 9: 106-133.

Dahl, C. (2009), "Energy Demand and Supply Elasticities," in: Owens, A.D. (Ed.), Energy Policy, 72-94, EOLSS Publications. 
Dahl, C., and T.E. Duggan (1996), "US Energy Product Supply Elasticities: A Survey and Application to the US Oil Market," Resource and Energy Economics, 18: 243-263.

Deryugina, T., A. MacKay, and J. Reif (2020), "The Long-Run Dynamics of Electricity Demand: Evidence from Municipal Aggregation," American Economic Journal: Applied Economics, 12: 86-114.

Eichner, T., and R. Pethig (2011), "Carbon Leakage, the Green Paradox, and Perfect Future Markets," International Economic Review, 52 :767-805.

Eyer, J.N. (2015), "The Effect of the Shale Gas Boom on Greenhouse Gas Emissions: Accounting for Coal Exports," mimeo, North Carolina State University.

Feng, K., S.J. Davis, L. Sun, and K. Hubacek (2015), "Drivers of the US CO2 Emissions 1997-2013," Nature Communications, 6, 7714.

Felder, S., and T.F. Rutherford (1993), "Unilateral CO2 Reductions and Carbon Leakage: The Consequences of International Trade in Oil and Basic Materials," Journal of Environmental Economics and Management, 25: 162-176.

Fischer, C., and S.W. Salant (2017), "Balancing the Carbon Budget for Oil: The Distributive Effects of Alternative Policies," European Economic Review, 99: 191-215.

Garcia-Cerrutti, L.M. (2000), "Estimating Elasticities of Residential Energy Demand from Panel County Data Using Dynamic Random Variables Models with Heteroskedastic and Correlated Error Terms," Resource and Energy Economics, 22: 355-366.

Gaudet, G., and P. Lasserre (1988), "On Comparing Monopoly and Competition in Exhaustible Resource Exploitation," Journal of Environmental Economics and Management, 15: 412-418.

Gerlagh, R, and O. Kuik (2014), "Spill or Leak? Carbon Leakage with International Technology Spillovers: A CGE Analysis," Energy Economics, 45: 381-388.

Harstad, B. (2012), "Buy Coal! A Case for Supply-Side Environmental Policy," Journal of Political Economy, 120: 77-115.

Henriet, F., and K. Schubert (2019), "Is Shale Gas a Good Bridge to Renewables? An Application to Europe," Environmental and Resource Economics, 72: 721-763.

Howarth, R.W., R. Santoro, and A. Ingraffea (2011), "Methane and the Greenhouse-Gas Footprint of Natural Gas from Shale Formations - A Letter," Climatic Change, 106: 679-690.

Hoel, M. (1984), "Extraction of a Resource with a Substitute for Some of Its Uses," Canadian Journal of Economics, 17: 593-602.

Hoel, M. (1994), "Efficient Climate Policy in the Presence of Free Riders," Journal of Environmental Economics and Management, 27: 259-274.

Hotelling, H. (1931), "The Economics of Exhaustible Resources," Journal of Political Economy, 39: 137-175. 
IPCC (2014), Mitigation of Climate Change - Contribution of Working Group III to the Fifth Assessment Report of the Intergovernmental Panel on Climate Change, Edenhofer, O., R. Pichs-Madruga, Y. Sokona, E. Farahani, S. Kadner, K. Seyboth, A. Adler, I. Baum, S. Brunner, P. Eickemeier, B. Kriemann, J. Savolainen, S. Schlömer, C. von Stechow, T. Zwickel, and J.C. Minx (Eds.), Cambridge University Press.

Jacoby, H.D., F.M. O'Sullivan, and S. Paltsev (2011), "The Influence of Shale Gas on US Energy and Environmental Policy," Economics of Energy and Environmental Policy, 1: $37-51$.

Knittel, C.R., K. Metaxoglou, A. Soderbery, and A. Trindade (2018), "Does US Export Global Warming? Coal Exports and the Shale Gas Boom," MIT-CEEPR Working Papers, 2018-013.

Knittel, C.R., K. Metaxoglou, and A. Trindade (2015), "Natural Gas Prices and Coal Displacement: Evidence from Electricity Markets," MIT-CEEPR Working Papers, 2015013.

Knittel, C.R., K. Metaxoglou, and A. Trindade (2016), "Are We Fracked? The Impact of Falling Gas Prices and the Implications for Coal-to-Gas Switching and Carbon Emissions," Oxford Review of Economic Policy, 32: 241-259.

Kotchen, M.J., and E.T. Mansur (2016), "Correspondence: Reassessing the Contribution of Natural Gas to US CO2 Emission Reductions since 2007," Nature Communications, 7, 10648 .

Labys, W.C., S. Paik, and A.M. Liebenthal (1979), "An Econometric Simulation Model of the US Market for Steam Coal," Energy Economics, 1: 19-26.

Li, R., R. Joyeux, and R.D. Ripple (2014), "International Natural Gas market Integration," Energy Journal, 35: 159-179.

Light, M.K. (1999), "Coal Subsidies and Global Carbon Emissions," Energy Journal, 20: $117-148$.

Light, M.K., C.D. Kolstad, and T.F. Rutherford (1999), "Coal Markets, Carbon Leakage, and the Kyoto Protocol," University of Colorado at Boulder Discussion Papers, 99-23.

Linn, J., and L. Muehlenbachs (2018), "The Heterogeneous Impacts of Low Natural Gas Prices on Consumers and the Environment," Journal of Environmental Economics and Management, 89: 1-28.

Maddala, G.S., R.P. Trost, H. Li, and F. Joutz (1997), "Estimation of Short-Run and Long-Run Elasticities of Energy Demand from Panel Data Using Shrinkage Estimators," Journal of Business and Economic Statistics, 15: 90-100.

Marks, L. (2018), "The Abatement Cost of Methane Emissions from Natural Gas Production," mimeo, University of California, Santa Barbara.

Markusen, J.R. (1975), "International Externalities and Optimal Tax Structures," Journal of International Economics, 5: 15-29. 
Metcalf, G.E. (2009), "Designing a Carbon Tax to Reduce US Greenhouse Gas Emissions," Review of Environmental Economics and Policy, 3: 63-83.

Michielsen, T. (2014), "Brown Backstops versus the Green Paradox," Journal of Environmental Economics and Management, 68: 87-110.

Newell, R.G., B.C. Prest, and A. Vissing (2019), "Trophy Hunting vs. Manufacturing Energy: The Price-Responsiveness of Shale Gas," Journal of the Association of Environmental and Resource Economists, 6: 391-431.

Paul, A., E. Myers, and K. Palmer (2009), "A Partial Adjustment Model of U.S. Electricity Demand by Region, Season, and Sector," RFF Discussion Papers, 08-50.

van der Ploeg, F., and C. Withagen (2014), "Growth, Renewables, and the Optimal Carbon Tax," International Economic Review, 55: 283-311.

Ritter, H., and M. Schopf (2014), "Unilateral Climate Policy: Harmful or Even Disastrous?," Environmental and Resource Economics, 58: 155-178.

Sebi, C. (2019), "Explaining the Increase in Coal Consumption Worldwide," The Conversation, February 24, 2019.

Available at https://theconversation.com/explaining-the-increase-in-coal-consumption-wo

Sinn, H.-W. (2008), "Public Policies Against Global Warming: A Supply Side Approach," International Tax and Public Finance, 15: 360-394.

Truby, J., and M. Paulus (2012), "Market Structure Scenarios in International Steam Coal Trade," Energy Journal, 33: 91-123. 


\title{
Online Appendix to "Unilateral CO2 Reduction Policy with More than One Carbon Energy Source"
}

\author{
by \\ Julien Xavier Daubanes \\ University of Geneva (GSEM), MIT (CEEPR), and CESifo \\ E-mail address: julien.daubanes@unige.ch \\ Fanny Henriet \\ Paris School of Economics (CNRS) \\ E-mail address: fanny.henriet@psemail.eu \\ and \\ Katheline Schubert \\ Paris School of Economics, University Paris 1, and CESifo \\ E-mail address: schubert@univ-paris1.fr
}

September 2020

In order to alleviate notations in the following appendices, functions' arguments may be omitted as long as it does not cause ambiguity.

\section{A Proofs of the Results of the Baseline Model}

\section{Proof of Proposition 1}

As explained in the main text, the equilibrium price $p$ is characterized by equation (5).

When $\tau^{H}=0, p$ is the laissez-faire price characterized in (2), which we will denote by $p^{L F}$. The assumptions presented in the main text imply that $D^{H}(p)+D^{F}(p)$ and $S_{c}(p)+S_{g}(p)$ are respectively strictly decreasing and increasing and cross once and only once at $p^{L F}>0$.

For a given $\tau^{H}>0$, the strict monotonicity and continuity of demand and supply in (5) ensure that when it exists the equilibrium price $p>0$ is determined uniquely as the 
continuous function of $\tau^{H}$ that we denote by $p\left(\tau^{H}\right)$. In this case, the total differentiation of (5) with respect to $p$ and $\tau^{H}$ yields

$$
\frac{d p}{d \tau^{H}}=\frac{\theta_{c}\left(S_{c}^{\prime}-D^{F \prime}\right)+\theta_{g} S_{g}^{\prime}}{S_{c}^{\prime}+S_{g}^{\prime}-D^{H \prime}-D^{F^{\prime}}}>0
$$

which is clearly strictly positive. It follows that when it exists $p\left(\tau^{H}\right)$ is differentiable and strictly increasing.

By its definition above, $p^{L F}=p(0)$. It follows that the equilibrium price $p\left(\tau^{H}\right)$ exists for sufficiently low tax levels $\tau^{H}$. Sufficiently high tax levels are incompatible with the competitive equilibrium characterized by (5) for two reasons.

First, keeping in mind that $p_{c}<p_{g}<p$ by (4), there may be an upper bound to the admissible tax levels which we will denote by $\bar{\tau}$ which, if it exists, is such that $p_{c}=p(\bar{\tau})-\theta_{c} \bar{\tau}=0$. Therefore, $p(\bar{\tau})=\theta_{c} \bar{\tau}$, so that $\bar{\tau}$ is characterized by

$$
D^{H}\left(\theta_{c} \bar{\tau}\right)+D^{F}(0)=S_{c}(0)+S_{g}\left(\left(\theta_{c}-\theta_{g}\right) \bar{\tau}\right) .
$$

Since $D^{H}(0)+D^{F}(0)>S_{c}(0)+S_{g}(0)$ and the left-hand side and right-hand side of (A.2) are respectively decreasing and increasing in $\bar{\tau}$, this upper bound is strictly positive if it exists. All tax levels $\tau>\bar{\tau}$ are incompatible with the balance of energy supply and demand as expressed in (5).

Second, since gas is not tradable, the equilibrium in (5) excludes tax levels such that the domestic demand $D^{H}$ falls short of the domestic gas supply $S_{g}$. Restrict attention to tax levels $\tau^{H} \leq \bar{\tau}$ which ensure that, by (5), the domestic demand for coal is $D^{H}\left(p\left(\tau^{H}\right)\right)$ $S_{g}\left(p\left(\tau^{H}\right)-\theta_{g} \tau^{H}\right)=S_{c}\left(p\left(\tau^{H}\right)-\theta_{c} \tau^{H}\right)-D^{F}\left(p\left(\tau^{H}\right)-\theta_{c} \tau^{H}\right)$. Note that, in this context, the domestic demand for coal is decreasing in $\tau^{H}$ : Indeed, in the right-hand side of the previous equality, (A.1) implies

$$
\frac{d p_{c}}{d \tau^{H}}=\frac{d\left(p-\theta_{c} \tau^{H}\right)}{d \tau^{H}}=\frac{d p}{d \tau^{H}}-\theta_{c}=\frac{-\left(\theta_{c}-\theta_{g}\right) S_{g}^{\prime}+\theta_{c} D^{H \prime}}{S_{c}^{\prime}+S_{g}^{\prime}-D^{H \prime}-D^{F \prime}},
$$

which is strictly negative. It follows that there may exist $\overline{\bar{\tau}}>0$ such that $D^{H}\left(p\left(\tau^{H}\right)\right)-$ $S_{g}\left(p\left(\tau^{H}\right)-\theta_{g} \tau^{H}\right)$ is nonnegative if and only if $\tau^{H}<\overline{\bar{\tau}}$.

To sum up, for all tax levels $\tau^{H}<\min (\bar{\tau}, \overline{\bar{\tau}})>0$, the equilibrium price $p$ exists and is unique. This proves the first part of the proposition. The rest of the proposition follows directly from (4) and the functions defined in the main text.

\section{Proof of Lemma 1}

Lemma 1-like the rest of the analysis - considers an marginal change in $\tau^{H}$ in the neighborhood of the laissez-faire equilibrium in which $\tau^{H}=0$. In this neighborhood, $p \sim p_{c} \sim p_{g}$. Using our notation $\xi_{X} \equiv|q d X / d q|>0$ for the absolute value of the elasticity of any function $X(q)$ with respect to its argument, (A.1) becomes

$$
\frac{d p}{d \tau^{H}}=\frac{\theta_{c}\left(S_{c} \xi_{S_{c}}+D^{F} \xi_{D^{F}}\right)+\theta_{g} S_{g} \xi_{S_{g}}}{S_{c} \xi_{S_{c}}+S_{g} \xi_{S_{g}}+D^{H} \xi_{D^{H}}+D^{F} \xi_{D^{F}}}>0,
$$

which shows that, all other things held constant, $d p / d \tau^{H}$ is larger as $\xi_{D^{H}}$ is lower. This proves Lemma 1. 


\section{Proof of Lemma 2}

Coal supply, in the Home country and in the Foreign country, is an increasing function of the coal producer price $p_{c}=p-\theta_{c} \tau^{H}$. The differentiation of $p_{c}$ with respect to $\tau^{H}$ yields (A.3), which shows that $d p_{c} / d \tau^{H}$ is strictly negative. In turn, this shows that coal production decreases with $\tau^{H}$ :

$$
\frac{d S_{c}}{d \tau^{H}}=S_{c}^{\prime} \frac{d p_{c}}{d \tau^{H}}<0
$$

In the neighborhood of the laissez-faire equilibrium, equations (A.3) and (A.5) yield:

$$
\frac{d S_{c}}{d \tau^{H}}=-S_{c} \xi_{S_{c}} \frac{\left(\theta_{c}-\theta_{g}\right) S_{g} \xi_{S_{g}}+\theta_{c} D^{H} \xi_{D^{H}}}{S_{c} \xi_{S_{c}}+S_{g} \xi_{S_{g}}+D^{H} \xi_{D^{H}}+D^{F} \xi_{D^{F}}} .
$$

In the neighborhood of the laissez-faire equilibrium, energy demands and supplies as well as elasticities only depend on the laissez-faire equilibrium price $p^{L F}$, and not on emission coefficients $\theta_{c}$ and $\theta_{g}$. Therefore, the right-hand side of (A.6) is increasing in $\theta_{c}$ and decreasing in $\theta_{g}$. Besides, treating elasticities as parameters, basic derivations of the right-hand side of (A.6) with respect to elasticities, other things held unchanged, show that $d S_{c} / d \tau^{H}$ is increasing with $\xi_{D^{H}}$ and $\xi_{S_{c}}$. This proves the lemma.

\section{Proof of Proposition 2 and Lemma 3}

Gas supply in the Home country is an increasing function of the gas producer price $p_{g}=p-\theta_{g} \tau^{H}$. The differentiation of $p_{g}$ with respect to $\tau^{H}$ yields:

$$
\frac{d p_{g}}{d \tau^{H}}=\frac{d p}{d \tau^{H}}-\theta_{g}=\frac{\left(\theta_{c}-\theta_{g}\right)\left(S_{c}^{\prime}-D^{F \prime}\right)+\theta_{g} D^{H \prime}}{S_{c}^{\prime}+S_{g}^{\prime}-D^{H \prime}-D^{F \prime}} .
$$

Therefore, $d p_{g} / d \tau^{H}>0$ (and $\left.d S_{g} / d p>0\right)$ is equivalent to $\left(\theta_{c}-\theta_{g}\right)\left(S_{c}^{\prime}-D^{F \prime}\right)+\theta_{g} D^{H \prime}>0$, which is also

$$
\frac{\theta_{c}-\theta_{g}}{\theta_{g}}>\frac{-D^{H \prime}}{S_{c}^{\prime}-D^{F \prime}} .
$$

In the neighborhood of the laissez-faire equilibrium, this condition may be written in elasticity terms as condition (7) of the main text:

$$
r=\frac{\theta_{c}-\theta_{g}}{\theta_{g}}>\frac{D^{H} \xi_{D^{H}}}{D^{F} \xi_{D^{F}}+S_{c} \xi_{S_{c}}}=r_{0} .
$$

This proves the first part of Proposition 2. The rest follows immediately from the analysis of $(7)$.

Lemma 3 further examines the policy-induced change in gas production:

$$
\frac{d S_{g}}{d \tau^{H}}=S_{g}^{\prime} \frac{d p_{g}}{d \tau^{H}}
$$

In the neighborhood of the laissez-faire equilibrium, equations (A.9) and (A.7) yield:

$$
\frac{d S_{g}}{d \tau^{H}}=S_{g} \xi_{S_{g}} \frac{\left(\theta_{c}-\theta_{g}\right)\left(S_{c} \xi_{S_{c}}+D^{F} \xi_{D^{F}}\right)-\theta_{g} D^{H} \xi_{D^{H}}}{S_{c} \xi_{S_{c}}+S_{g} \xi_{S_{g}}+D^{H} \xi_{D^{H}}+D^{F} \xi_{D^{F}}} .
$$

Lemma 3 assumes that (7) holds so that $d S_{g} / d \tau^{H}>0$. 
The same remark as above applies: In the neighborhood of the laissez-faire equilibrium, quantities and elasticities do not depend on emission coefficients. Therefore, the right-hand side of equation (A.10) is increasing with $\theta_{c}$ and decreasing with $\theta_{g}$. Besides, other things held constant, one can directly see that it is decreasing with $\xi_{D^{H}}$. Moreover, basic derivations easily show that it is increasing with $\xi_{D^{F}}, \xi_{S_{c}}$ and $\xi_{S_{g}}$. This proves Lemma 3.

\section{Proof of Corollary 1}

Domestic emissions are $e^{H}=\theta_{c} D^{H}-\left(\theta_{c}-\theta_{g}\right) S_{g}$. The differentiation of $e^{H}$ with respect to $\tau^{H}$ yields:

$$
\begin{aligned}
\frac{d e^{H}}{d \tau^{H}} & =\theta_{c} D^{H \prime} \frac{d p}{d \tau^{H}}-\left(\theta_{c}-\theta_{g}\right) S_{g}^{\prime}\left(\frac{d p}{d \tau^{H}}-\theta_{g}\right) \\
& =\frac{\left[\theta_{c}^{2} D^{H \prime}-\left(\theta_{c}-\theta_{g}\right)^{2} S_{g}^{\prime}\right]\left(S_{c}^{\prime}-D^{F \prime}\right)+\theta_{g}^{2} S_{g}^{\prime} D^{H \prime}}{S_{c}^{\prime}+S_{g}^{\prime}-D^{H \prime}-D^{F \prime}},
\end{aligned}
$$

which is strictly negative. This is the first point of the corollary.

Coal exports by the Home country are equal to coal imports by the Foreign country, that is $S_{c}^{H}-\left(D^{H}-S_{g}\right)=D^{F}-S_{c}^{F}$. On the right-hand side, Foreign demand and coal supply are determined by the coal producer price $p_{c}$, which has already been proved to decrease with the tax. It follows that coal exports unambiguously increase with the tax. This is the second point of the corollary.

Foreign emissions $e^{F}=\theta_{c} D^{F}\left(p_{c}\right)$ are a decreasing function of the coal producer price, which itself decreases with the tax. It follows that the domestic policy $\tau^{H}$ systematically entails carbon leakage:

$$
\frac{d e^{F}}{d \tau^{H}}=\theta_{c} D^{F \prime} \frac{-\left(\theta_{c}-\theta_{g}\right) S_{g}^{\prime}+\theta_{c} D^{H \prime}}{S_{c}^{\prime}+S_{g}^{\prime}-D^{H \prime}-D^{F \prime}}>0
$$

This proves the last point of Corollary 1.

\section{Proof of Lemma 4}

For brevity, we will denote the leakage rate by $\rho \equiv\left(d e^{F} / d \tau^{H}\right) /\left(-d e^{H} / d \tau^{H}\right)$. Equations (A.11) and (A.12) directly imply:

$$
\rho=\frac{\frac{d e^{F}}{d \tau^{H}}}{-\frac{d e^{H}}{d \tau^{H}}}=\frac{\theta_{c} D^{F^{\prime}}\left[-\left(\theta_{c}-\theta_{g}\right) S_{g}^{\prime}+\theta_{c} D^{H \prime}\right]}{-\left[\theta_{c}^{2} D^{H \prime}-\left(\theta_{c}-\theta_{g}\right)^{2} S_{g}^{\prime}\right]\left(S_{c}^{\prime}-D^{F^{\prime}}\right)-\theta_{g}^{2} S_{g}^{\prime} D^{H \prime}} .
$$

Dividing both the numerator and the denominator by $\theta_{g}^{2}$ and making use of the notation introduced in the main text $r=\left(\theta_{c}-\theta_{g}\right) / \theta_{g}$, one obtains:

$$
\rho=\frac{D^{F \prime}\left[(r+1)^{2} D^{H \prime}-(r+1) r S_{g}^{\prime}\right]}{\left[-(r+1)^{2} D^{H \prime}+r^{2} S_{g}^{\prime}\right]\left(S_{c}^{\prime}-D^{F \prime}\right)-S_{g}^{\prime} D^{H \prime}} .
$$

In the neighborhood of the laissez-faire equilibrium, one can rewrite the leakage rate as in (9) of the main text after rearranging terms:

$$
\rho=\frac{\frac{D^{H} \xi_{D^{H}}}{S_{g} \xi_{S_{g}}}(r+1)^{2}+(r+1) r}{\left(\frac{D^{H} \xi_{D^{H}}}{S_{g} \xi_{S_{g}}}(r+1)^{2}+r^{2}\right)\left(\frac{S_{c} \xi_{S_{c}}}{D^{F} \xi_{D^{F}}}+1\right)+\frac{D^{H} \xi_{D^{H}}}{D^{F} \xi_{D^{F}}}} .
$$


Basic derivations show that the leakage rate is larger as $\xi_{S_{g}}$ and $\xi_{D^{F}}$ are higher and as $\xi_{D^{H}}$ and $\xi_{S_{c}}$ are lower. This is the first point of the lemma.

The second point of Lemma 4 tells that the leakage rate is always greater when $r>0$ than when $r=0$, other things held unchanged, as if the two energy sources were homogenously polluting.

For $r=0$, the leakage rate in (A.13) becomes:

$$
\rho_{r=0}=\frac{D^{F \prime}}{-\left(S_{c}^{\prime}-D^{F^{\prime}}\right)-S_{g}^{\prime}} .
$$

Therefore, the ratio of (A.13) over (A.14) is:

$$
\frac{\rho}{\rho_{r=0}}=\frac{\left[(r+1) r S_{g}^{\prime}-(r+1)^{2} D^{H \prime}\right]\left(S_{c}^{\prime}-D^{F \prime}+S_{g}^{\prime}\right)}{\left[-(r+1)^{2} D^{H \prime}+r^{2} S_{g}^{\prime}\right]\left(S_{c}^{\prime}-D^{F \prime}\right)-S_{g}^{\prime} D^{H \prime}} .
$$

The denominator of (A.15) can be rewritten as follows:

$$
\begin{aligned}
& {\left[-(r+1)^{2} D^{H \prime}+r^{2} S_{g}^{\prime}\right]\left(S_{c}^{\prime}-D^{F \prime}\right)-S_{g}^{\prime} D^{H \prime}=} \\
& {\left[-(r+1)^{2} D^{H \prime}+(r+1) r S_{g}^{\prime}\right]\left(S_{c}^{\prime}-D^{F \prime}+S_{g}^{\prime}\right)} \\
& -S_{g}^{\prime}\left[\left[-(r+1)^{2} D^{H \prime}+(r+1) r S_{g}^{\prime}\right]\right]-r S_{g}^{\prime}\left(S_{c}^{\prime}-D^{F \prime}\right)-S_{g}^{\prime} D^{H \prime},
\end{aligned}
$$

which simplifies as

$$
\begin{aligned}
& {\left[-(r+1)^{2} D^{H \prime}+r^{2} S_{g}^{\prime}\right]\left(S_{c}^{\prime}-D^{F \prime}\right)-S_{g}^{\prime} D^{H \prime}=} \\
& {\left[-(r+1)^{2} D^{H \prime}+(r+1) r S_{g}^{\prime}\right]\left(S_{c}^{\prime}-D^{F \prime}+S_{g}^{\prime}\right)} \\
& +S_{g}^{\prime}\left[(r+1)^{2} D^{H \prime}-(r+1) r S_{g}^{\prime}-r\left(S_{c}^{\prime}-D^{F \prime}\right)-D^{H \prime}\right] .
\end{aligned}
$$

With this simplification, (A.15) implies that $\frac{\rho}{\rho_{r=0}}>1$ if and only if

$$
(r+1)^{2} D^{H \prime}-(r+1) r S_{g}^{\prime}-r\left(S_{c}^{\prime}-D^{F \prime}\right)-D^{H \prime}<0,
$$

which simplifies to

$$
\left(r^{2}+2 r\right) D^{H \prime}-(r+1) r S_{g}^{\prime}-r\left(S_{c}^{\prime}-D^{F \prime}\right)<0 .
$$

It is straightforward to see that all terms in (A.16) are strictly negative so that the condition is satisfied for all $r>0$, which proves the second point of the lemma.

\section{Proof of Proposition 3}

World emissions are $e^{W}=e^{H}+e^{F}$. Therefore the differentiation of $e^{W}$ with respect to $\tau^{H}$ yields: $\frac{d e^{W}}{d \tau^{H}}=\frac{d e^{H}}{d \tau^{H}}(1-\rho)$ : As domestic emissions decrease with the tax, world emissions increase if and only if $\rho>1$, that is when the leakage rate is more than $100 \%$.

Using equation (A.13) and rearranging terms, one obtains that $\rho>1$ is equivalent to

$$
P(r)=r^{2}\left(D^{H \prime}-S_{g}^{\prime}\right) S_{c}^{\prime}+r\left(-S_{g}^{\prime} D^{F \prime}+2 S_{c}^{\prime} D^{H \prime}\right)+\left(S_{c}^{\prime}+S_{g}^{\prime}\right) D^{H \prime}>0,
$$

which is condition (10) in the main text.

As explained above, our analysis focuses on infinitesimal variations in a neighborhood of the laissez-faire equilibrium in which $\tau^{H}=0$. That means that in (A.17), derivatives 
are evaluated around $\tau^{H}=0$ and, therefore, do not depend on pollution intensity parameters in $r=\left(\theta_{c}-\theta_{g}\right) / \theta_{g}$. It follows that $P(r)$ in (A.17) is a second degree polynomial function of $r$, defined on $r \in[0,+\infty)$. Since its second degree coefficient $\left(D^{H \prime}-S_{g}^{\prime}\right) S_{c}^{\prime}$ is negative, it satisfies $\lim _{r \mapsto+\infty} P(r)=-\infty$. Moreover, it satisfies $P(0)=\left(S_{c}^{\prime}+S_{g}^{\prime}\right) D^{H^{\prime}}<0$.

If the polynomial's discriminant

$$
\Delta=S_{g}^{\prime 2} D^{F \prime 2}+4\left(S_{c}^{\prime}+S_{g}^{\prime}-D^{F \prime}-D^{H \prime}\right) S_{g}^{\prime} S_{c}^{\prime} D^{H \prime}
$$

is strictly negative, $P(r)$ is always negative, meaning that the leakage rate is always smaller than $100 \%$. On the other hand if the discriminant is strictly positive, $P(r)$ admits two real roots and will be positive - so the leakage rate will be more than $100 \%$ for values of $r$ in between these roots. This necessary condition for the possibility that $d e^{W} / d \tau^{H}$ be positive is expressed in (11), which is a simple reformulation of $\Delta>0$ in elasticity terms using (A.18):

$$
\frac{S_{g} \xi_{S_{g}}\left(D^{F} \xi_{D^{F}}\right)^{2}}{D^{H} \xi_{D^{H}} S_{c} \xi_{S_{c}}}>D^{H} \xi_{D^{H}}+D^{F} \xi_{D^{F}}+S_{c} \xi_{S_{c}}+S_{g} \xi_{S_{g}}
$$

This proves the first point of Proposition 3.

The second point of the proposition is shown in the main text immediately following equation (8): Given that coal production is systematically reduced by the policy, world emissions may only increase if $d S_{g} / d \tau^{H}>0$.

The third point of Proposition 3 directly results from the analysis of (11), in which the role of elasticity terms, other things held constant, is straightforward.

The fourth and last point of the proposition can be proven as follows. If the condition $\Delta>0$ is satisfied, the two roots $\underline{r}<\bar{r}$ of $P(r)$ are

$$
\underline{r} \equiv \frac{\left(-S_{g}^{\prime} D^{F^{\prime}}+2 S_{c}^{\prime} D^{H \prime}\right)-\sqrt{\Delta}}{2\left(S_{g}^{\prime}-D^{H \prime}\right) S_{c}^{\prime}}
$$

and

$$
\bar{r} \equiv \frac{\left(-S_{g}^{\prime} D^{F \prime}+2 S_{c}^{\prime} D^{H \prime}\right)+\sqrt{\Delta}}{2\left(S_{g}^{\prime}-D^{H \prime}\right) S_{c}^{\prime}} .
$$

When they exist, these two roots can be shown to be positive as follows. First, following a well-known property of second degree polynomials, the roots' product is

$$
\underline{r} \bar{r}=\frac{-\left(S_{c}^{\prime}+S_{g}^{\prime}\right) D^{H \prime}}{\left(S_{g}^{\prime}-D^{H \prime}\right) S_{c}^{\prime}},
$$

which is positive, implying that the two roots have the same sign. Second, the roots' sum is

$$
\underline{r}+\bar{r}=\frac{-S_{g}^{\prime} D^{F \prime}+2 S_{c}^{\prime} D^{H \prime}}{\left(S_{g}^{\prime}-D^{H \prime}\right) S_{c}^{\prime}} .
$$

In this fraction, the denominator is positive, and it can easily be shown that the positivity of $\Delta$ in (A.18) implies that the numerator is positive as well. Therefore, the roots' sum is positive. Having already established that the roots have the same sign, one can conclude that this sign is positive. 


\section{Proof of Proposition 4}

Totally differentiating the equilibrium condition (15) with respect to $p, \tau^{H}$ and $\tau^{F}$, and rearranging terms, one obtains

$$
\left(S_{c}^{\prime}+S_{g}^{\prime}-D^{H \prime}-D^{F \prime}\right) d p=\left(\theta_{c}\left(S_{c}^{\prime}-D^{F \prime}\right)+\theta_{g} S_{g}^{\prime}\right) d \tau^{H}-\theta_{c} D^{F \prime} d \tau^{F} .
$$

Proposition 4 assumes that the Foreign country's emissions are limited as per (16), which implies that the coal price $p_{c}=p-\theta_{c} \tau^{H}+\theta_{c} \tau^{F}$ therein, as given in (14), is held unchanged. Its total derivative with respect to $p, \tau^{H}$ and $\tau^{F}$ is, therefore, zero:

$$
d p-\theta_{c} d \tau^{H}+\theta_{c} d \tau^{F}=0
$$

Combining equations (A.21) and (A.22) by substituting $d p$, one obtains

$$
\frac{d \tau^{F}}{d \tau^{H}}=\frac{-D^{H \prime}+\frac{\theta_{c}-\theta_{g}}{\theta_{c}} S_{g}^{\prime}}{-D^{H \prime}+S_{c}^{\prime}+S_{g}^{\prime}},
$$

from which equation (17) is derived after using the elasticity notations of the main text. This proves Proposition 4.

\section{B Variations in Domestic and Foreign Energy Demand Elasticities}

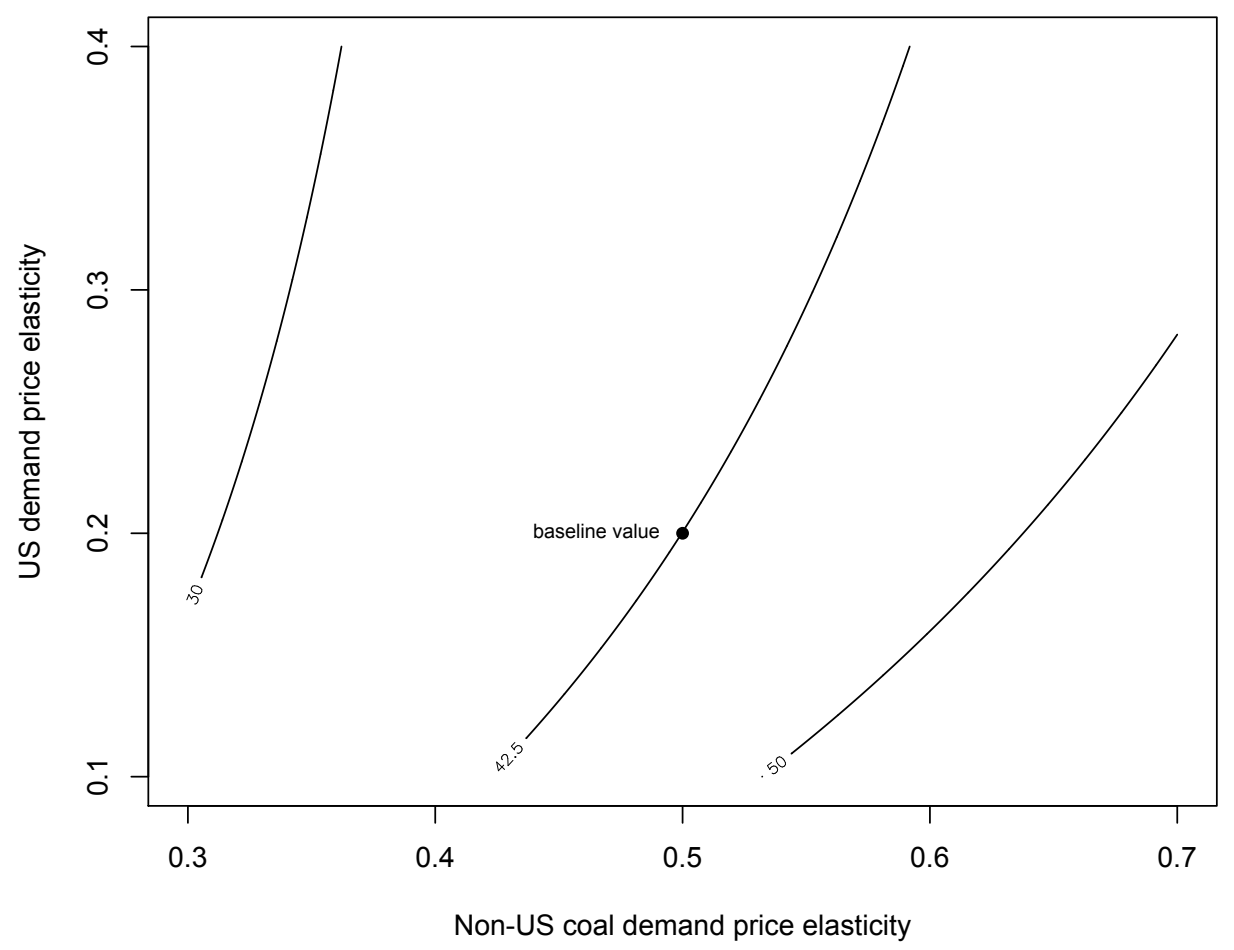

Figure 7: Curves of iso-leakage-rate and demand elasticities 


\section{International Gas Trade}

In this appendix, we present a slightly modified version of the model of Section III's main analysis that considers the international trade of gas.

The description of the equilibrium with international gas trade requires the following additional notations: Home consumption of gas (respectively, coal) will be denoted by $X_{g}^{H}$ (respectively, $X_{g}^{F}$ ), while Foreign consumption of gas (respectively, coal) will be denoted $X_{g}^{F}$ (respectively, $X_{c}^{F}$ ).

The differences with the main analysis are as follows. First and foremost, gas can be exported from the Home country to the rest of the world at some quadratic total transportation costs. The price of (imported) gas in the Foreign country is $p_{g}+T_{g}\left(X_{g}^{F}\right)$ where the marginal transportation cost $T_{g}\left(X_{g}^{F}\right)=t_{g} X_{g}^{F}$ is linear and $t_{g}>0$ is constant. Second, coal exports entail similar quadratic total transportation costs: The price in the Foreign country of coal imported from the domestic economy is $p_{c}+T_{c}\left(X_{c}^{F}-S_{c}^{F}\right)$ where $T_{c}\left(X_{c}^{F}-S_{c}^{F}\right)=t_{c}\left(X_{c}^{F}-S_{c}^{F}\right)$ is linear in domestic exports and $t_{c}>0$ is constant. In the presence of the domestic $\mathrm{CO} 2$ penalty $\tau^{H}$, the main equations describing the competitive equilibrium become:

$$
\begin{aligned}
S_{c}^{F}\left(p_{c}+T_{c}\right)+S_{c}^{H}\left(p_{c}\right) & =X_{c}^{H}+X_{c}^{F} ; \\
S_{g}\left(p_{g}\right) & =X_{g}^{H}+X_{g}^{F} ; \\
D^{H}\left(p_{c}+\theta_{c} \tau^{H}\right) & =X_{g}^{H}+X_{c}^{H} ; \\
p_{c}+T_{c} & =p_{g}+T_{g} ; \\
D^{F}\left(p_{c}+T_{c}\right) & =X_{g}^{F}+X_{c}^{F} ; \\
p_{c}+\theta_{c} \tau^{H} & =p_{g}+\theta_{g} \tau^{H} ; \\
T_{c} & =t_{c}\left(X_{c}^{F}-S_{c}^{F}\left(p+T_{c}\right)\right) ; \\
T_{g} & =t_{g} X_{g}^{F} .
\end{aligned}
$$

One can show that the above system has a unique interior solution at the laissez-faire equilibrium (i.e., with $\tau^{H}=0$ ) in which exports of both coal and gas are non zero if and only if

$$
\frac{t_{c}+t_{g}}{t_{c} t_{g}}>\frac{D^{H}(0)-S_{g}(0)-S_{c}^{H}(0)}{\left(\left(D^{F}-S_{c}^{F}\right)^{-1}\left(D^{H}(0)-S_{g}(0)-S_{c}^{H}(0)\right)\right)} .
$$

In the context of this interior equilibrium, and in a neighborhood of the laissez-faire equilibrium in which $\tau=0$, the total differentiation of the equilibrium system of equations yields the marginal effect of putting in place a tax at Home. Precisely, we find that a marginal increase in $\tau^{H}$ induces more gas to be produced in the Home country if and only if

$\frac{\theta_{c}-\theta_{g}}{\theta_{g}} \geq \frac{-D^{H \prime}\left(t_{c}+t_{g}+t_{g} t_{c}\left(S_{c}^{F^{\prime}}-D^{F^{\prime}}\right)\right)\left(1+t_{c} S_{c}^{F \prime}\right)}{t_{g}\left(S_{c}^{F^{\prime}}+S_{c}^{H \prime}-D^{F \prime}\right)+t_{c} t_{g}\left(S_{c}^{F \prime}-D^{F^{\prime}}\right)\left(S_{c}^{F^{\prime}}+S_{c}^{H \prime}\left(1+t_{c} S_{c}^{F^{\prime}}\right)\right)+t_{c} S_{c}^{H \prime}\left(1+t_{c} S_{c}^{F \prime}\right)}$.

This condition is the counterpart of (7).

Moreover, a marginal increase in the domestic CO2 tax induces more CO2 emissions 
worldwide (more-than-100\% leakage) if and only if

$$
\begin{aligned}
& -S_{g}^{\prime}\left(\left(S_{c}^{H \prime}-D^{H \prime}\right) \frac{t_{g}+t_{c} t_{g}\left(S_{c}^{F^{\prime}}-D^{F \prime}\right)+t_{c}}{1+t_{c} S_{c}^{F \prime}}+\frac{S_{c}^{F \prime}-D^{F \prime}}{1+t_{c} S_{c}^{F \prime}} t_{g}\right) \\
& -\left(\frac{\theta_{c}}{\theta_{g}}\right)^{2}\left[\frac{S_{c}^{F^{\prime}}}{1+t_{c} S_{c}^{F \prime}}\left(S_{g}^{\prime}-D^{H \prime}\right) t_{g}+S_{c}^{H \prime}\left(S_{g}^{\prime}-D^{H \prime}\right)\left(t_{g}+\frac{t_{c}}{1+t_{c} S_{c}^{F \prime}}\right.\right. \\
& \left.\left.-D^{F^{\prime}} \frac{t_{c} t_{g}}{1+t_{c} S_{c}^{F \prime}}\right)-\frac{t_{c} D^{H \prime} S_{c}^{H \prime}}{1+t_{c} S_{c}^{F \prime}}\right] \\
& +\frac{\theta_{c}}{\theta_{g}}\left[2 S_{c}^{H \prime} S_{g}^{\prime} \frac{t_{c}}{1+t_{c} S_{c}^{F \prime}}+2\left(\frac{S_{c}^{F \prime}}{1+t_{c} S_{c}^{F \prime}}+S_{c}^{H \prime}\right) S_{g}^{\prime} t_{g}-S_{c}^{H \prime} \frac{t_{c}}{1+t_{c} S_{c}^{F \prime}} D^{F \prime}\right. \\
& \left.-\left(\frac{S_{c}^{F \prime}}{1+t_{c} S_{c}^{F \prime}}+2 S_{c}^{H \prime}\right) \frac{t_{c}}{1+t_{c} S_{c}^{F \prime}} S_{g}^{\prime} t_{g} D^{F \prime}-\frac{D^{F \prime} t_{g} S_{g}^{\prime}}{\left(1+t_{c} S_{c}^{F \prime}\right)^{2}}+D^{H \prime} \frac{t_{c} S_{c}^{F \prime}}{1+t_{c} S_{c}^{F \prime}}\right]>0 .
\end{aligned}
$$

Although the full analysis of this extension goes beyond the scope of this paper, one can easily show that the latter condition may be satisfied, so that a more-than- $100 \%$ leakage rate making the unilateral domestic policy counterproductive is compatible with the international trade of gas.

Indeed, for example in the special case in which $S_{c}^{H \prime}=S_{c}^{F \prime}=0$, the above condition under which the policy is counterproductive becomes

$$
r>-t_{c} D^{H \prime}+\frac{D^{H \prime}}{D^{F \prime}} \frac{t_{g}+t_{c}}{t_{g}}
$$

which is obviously satisfied as gas becomes sufficiently clean compared with coal.

\section{Gas Supply in the Rest of the World}

In this appendix, we reexamine the basic model of the main text with the single following modification: Gas is produced not only in the Home country but also in the Foreign country. Like in the former, it is produced in the latter by a price-taking representative firm, which does not export it. Gas production in the rest of the world $S_{g}^{F}$-expressed in energy units - is given by the supply function of the foreign gas price $S_{g}^{F}=S_{g}^{F}\left(p_{g}^{F}\right)$, which is assumed nonnegative, differentiable and strictly increasing for all $p_{g}^{F}$. In the same way as for the Home country, coal and gas can equivalently be used to produce electricity energy, and jointly meet the foreign energy demand $D^{F}\left(p^{F}\right)$, where $p^{F}$ denotes the consumer energy price in the Foreign country.

In the context of this extension, the interesting equilibria are those in which coal and gas are used at the same time in the rest of the world. To focus on these situations, we consider that the following no-arbitrage condition holds:

$$
p^{F}=p_{g}^{F}=p_{c} .
$$

It follows from our assumptions that (5) becomes

$$
D^{H}(p)+D^{F}\left(p-\theta_{c} \tau^{H}\right)=S_{c}^{H}\left(p-\theta_{c} \tau^{H}\right)+S_{c}^{F}\left(p-\theta_{c} \tau^{H}\right)+S_{g}^{H}\left(p-\theta_{g} \tau^{H}\right)+S_{g}^{F}\left(p-\theta_{c} \tau^{H}\right),
$$

where $S_{g}^{H}$ now denotes the domestic production of gas, and the balance of the world energy market now also depends on the foreign supply of gas $S_{g}^{F}\left(p_{c}\right)$. The equality $p_{c}=p-\theta_{c} \tau^{H}$ still holds, as in the analysis of the main text. 
With this adjustment, equation (D.1) determines completely the equilibrium, instead of (5) in the main analysis.

The other implication of the production of gas in the Foreign country is that this gas generates $\mathrm{CO} 2$ emissions. The rest of the world's CO2 emissions become

$$
e^{F}=\theta_{c} D^{F}+\theta_{g} S_{g}^{F}
$$

including emissions due to the consumption of the local foreign gas.

Given these changes, the analysis is the same as in the absence of gas in the Foreign country. Following the same steps as in Appendix A, one obtains the following result: A tax on domestic emissions $\tau^{H}$ causes an increase in global emissions $e^{W}$ if and only if

$$
r^{2}\left(D^{H \prime}-S_{g}^{\prime}\right) S_{c}^{\prime}+r\left(-S_{g}^{H \prime} D^{F \prime}+2 S_{c}^{\prime} D^{H \prime}+S_{g}^{F \prime} D^{H \prime}\right)+\left(S_{c}^{\prime}+S_{g}^{\prime}+S_{g}^{F \prime}\right) D^{H \prime}
$$

is positive, instead of (A.17). The comparison of (D.3) with its counterpart (A.17) in the absence of foreign gas highlights that the two expressions only differ by the intervention of $S_{g}^{F^{\prime}}$ in the former, making (D.3) less likely to be positive. That means that the domestic CO2 reduction policy is less likely to cause a more-than- $100 \%$ leakage rate and is, equivalently, less likely to be counterproductive, in the presence of foreign gas.

Besides this adjustment, the analysis is not qualitatively modified by the presence of gas in the rest of the world. More precisely, (D.3) has positive roots and, therefore, there exist values of $r>0$ between these roots that induce a more-than-100\% leakage rate. The presence of foreign gas, therefore, yields results that can be summarized like in Subsection V.C.

\section{E Technical Progress in the Production of Gas, and Development of Non-Carbon Energy Sources}

Technical progress in the production of gas may be captured as follows. Replace the gas supply function by

$$
\alpha S_{g}\left(p_{g}\right)
$$

where $\alpha \geq 0$ is a multiplicative technological parameter. An increase of $\alpha$ from its value $\alpha=1$ in the analysis of the main text reflects, for any gas price $p_{g}$, an improvement in production conditions causing an increase in supply.

Similarly, the development of non-carbon energy sources may be represented as follows. Replace the (residual) demand functions for (coal and gas) carbon energy sources by

$$
\beta D^{F}\left(p_{c}\right)
$$

and

$$
\beta D^{H}(p),
$$

where $\beta \geq 0$ is a multiplicative parameter measuring the capacity of production from non-carbon energy sources. A decrease in $\beta$ from its value $\beta=1$ in the analysis of the main text reflects, for any price of coal and gas, an improvement in the production of non-carbon energy sources reducing the residual demand for carbon energy sources.

As explained in the main text, this appendix presents a complement to the paper's analysis of a unilateral CO2 reduction policy. Here, instead, we do away with the public policy so as to focus the analysis on the effect of both technical progress in gas production and the development of non-carbon energy sources. 
In this new context, the consumer energy price $p$ is only determined by the balance of the world energy market:

$$
\beta\left(D^{H}(p)+D^{F}(p)\right)=S_{c}(p)+\alpha S_{g}(p) .
$$

At the same time, price $p$ determines domestic CO2 emissions as per

$$
\theta_{c} \beta\left[D^{H}(p)-\alpha S_{g}(p)\right]+\theta_{g} \alpha S_{g}(p)=e^{H} .
$$

The total differentiation of the above system with respect to parameters $\alpha$ and $\beta$, evaluated in the neighborhood of the main text's case in which $\alpha=\beta=1$, yields

$$
\left(\begin{array}{cc}
A_{2} & -1 \\
A_{1} & 0
\end{array}\right)\left(\begin{array}{c}
d p \\
d e^{H}
\end{array}\right)=\left(\begin{array}{cc}
\left(\theta_{c}-\theta_{g}\right) S_{g}(p) & -\theta_{c} D^{H}(p) \\
S_{g}(p) & -\left(D^{H}(p)+D^{F}(p)\right)
\end{array}\right)\left(\begin{array}{l}
d \alpha \\
d \beta
\end{array}\right)
$$

where

$$
\begin{aligned}
& A_{1}=D^{H \prime}+D^{F \prime}-\left(S_{c}^{\prime}+S_{g}^{\prime}\right)<0, \\
& A_{2}=\theta_{c} D^{H \prime}-\left(\theta_{c}-\theta_{g}\right) S_{g}^{\prime}<0 .
\end{aligned}
$$

Inverting, one obtains

$$
\left(\begin{array}{c}
d p \\
d e^{H}
\end{array}\right)=\frac{1}{A_{1}}\left(\begin{array}{cc}
S_{g} & -\left(D^{H}+D^{F}\right) \\
-A_{1}\left(\theta_{c}-\theta_{g}\right) S_{g}+A_{2} S_{g} & A_{1} \theta_{c} D^{H}-A_{2}\left(D^{H}+D^{F}\right)
\end{array}\right)\left(\begin{array}{l}
d \alpha \\
d \beta
\end{array}\right) .
$$

Since $A_{1}<0$, the first line of system (E.1) implies the following effects of $\alpha$ and $\beta$ on the consumer energy price: $d p / d \alpha<0$ and $d p / d \beta>0$. That means that both technical progress in the production of gas $(d \alpha>0)$ and the development of non-carbon substitutes $(d \beta<0)$ induce a decrease in the world price for coal and gas.

Let us first examine the impact of technical progress in gas production. Given that $A_{1}<0$, it follows from (E.1) that a rise in $\alpha$ causes a decrease in domestic CO2 emissions if and only if $-A_{1}\left(\theta_{c}-\theta_{g}\right)+A_{2}>0$. Rearranging, the condition becomes

$$
r>\frac{D^{H \prime}}{D^{F \prime}-S_{c}^{\prime}}
$$

In other words, technical improvements in the production of gas induce a reduction of domestic CO2 emissions if and only if the rate of pollution increase from gas to coal is sufficiently high, as when gas is sufficiently less carbon intensive than coal.

In fact, condition (E.2) appears to be formally the same as condition (7): In other words, a reduction of domestic CO2 emissions commands to produce more gas if and only if an increase in gas supply reduces domestic CO2 emissions. This condition may write

$$
r>r_{0} .
$$

This formal, and intuitive, symmetry substantiates the claim of footnote 23 .

By contrast, $\mathrm{CO} 2$ emissions in the rest of the world are always increased as a result of technical progress in gas production. Indeed, a rise in $\alpha$ decreases the energy price $p$ and, therefore, the foreign consumption of coal $\beta D^{F}(p)$ and the resulting emissions $e^{F}=\theta_{c} \beta D^{F}(p)$.

As far as the world CO2 emissions are concerned, there are two basic cases. First, low values of the rate of pollution increase

$$
r \leq r_{0}
$$


imply that, as a consequence of technical progress in gas production, emissions increase both in the Home country and in the Foreign country, hence at the global level unambiguously.

Second, if $r>r_{0}$, gas-production technical improvements lead to a decrease in domestic emissions $e^{H}$ and a decrease in the world price $p$, causing foreign emissions $e^{F}=\theta_{c} \beta D^{F}(p)$ to increase. Using system (E.1) to characterize the effect on $e^{W}=e^{H}+e^{F}$ allows us to obtain the following: When domestic CO2 emissions are reduced by technical progress in gas production, i.e., when $-A_{1}\left(\theta_{c}-\theta_{g}\right)+A_{2}>0$, this reduction is accompanied by a leakage rate

$$
-\frac{d e^{F}}{d e^{H}}=-\frac{\theta_{c} D^{F \prime}}{-A_{1}\left(\theta_{c}-\theta_{g}\right)+A_{2}}=\frac{-\theta_{c} D^{F^{\prime}}}{-\left(\theta_{c}-\theta_{g}\right)\left(D^{F \prime}-S_{c}^{\prime}\right)+\theta_{g} D^{H \prime}},
$$

which is more than $100 \%$ if and only if

$$
-\theta_{c} D^{F^{\prime}}>-\left(\theta_{c}-\theta_{g}\right)\left(D^{F^{\prime}}-S_{c}^{\prime}\right)+\theta_{g} D^{H^{\prime}} .
$$

This condition may write as follows:

$$
r<\frac{-\left(D^{F \prime}+D^{H \prime}\right)}{S_{c}^{\prime}}
$$

The comparison of the threshold at the right-hand side of (E.3) with the $r_{0}$ threshold used above immediately shows that the latter is lower than the former. Therefore, for intermediate values of the rate $r$, such as

$$
r_{0}<r<\frac{-\left(D^{F \prime}+D^{H \prime}\right)}{S_{c}^{\prime}},
$$

technical progress in the production of gas, despite a decrease in domestic $\mathrm{CO} 2$ emissions, increases world CO2 emissions. However, for sufficiently high values

$$
r \geq \frac{-\left(D^{F \prime}+D^{H \prime}\right)}{S_{c}^{\prime}}
$$

as when gas is sufficiently less carbon intensive than coal, technical progress in gas production does induce domestic and world $\mathrm{CO} 2$ emissions to decrease. The above results are illustrated in Figure 8.

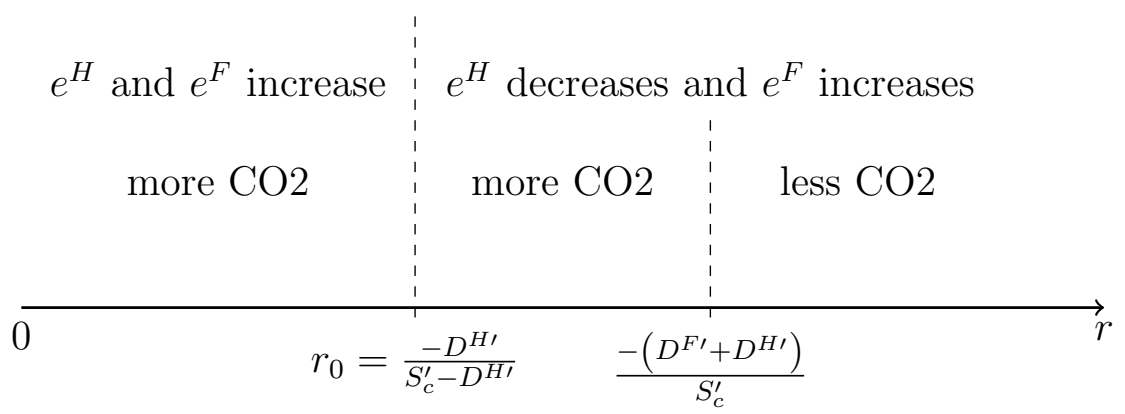

Figure 8: Technical progress in gas production, and domestic, foreign and world CO2 emissions 
Let us now turn to the impact of the development of non-carbon energy sources. The system (E.1) tells how a change in $\beta$ impacts domestic emissions $e^{H}$. As far as foreign emissions $e^{F}=\beta D^{F}(p)$ are concerned, they are affected both directly via $\beta$, and indirectly via the price $p$; the effect of $\beta$ on $p$ is also indicated by (E.1).

Formally, we obtain

$$
\begin{aligned}
\frac{d e^{W}}{d \beta} & =\frac{d e^{H}}{d \beta}+\frac{d e^{F}}{d \beta}=\frac{1}{A_{1}}\left(A_{1} \theta_{c} D^{H}-A_{2}\left(D^{H}+D^{F}\right)\right)+\theta_{c} D^{F}+\theta_{c} D^{F \prime} \frac{d p}{d \beta} \\
& =\frac{\theta_{c}\left(D^{F \prime}-S_{c}^{\prime}\right)-\theta_{g} S_{g}^{\prime}}{A_{1}}\left(D^{H}+D^{F}\right)+\theta_{c} D^{F^{\prime}} \frac{d p}{d \beta} .
\end{aligned}
$$

Using (E.1) to replace $d p / d \beta$, and rearranging, we finally obtain

$$
\frac{d e^{W}}{d \beta}=-\frac{1}{A_{1}}\left(\theta_{c} S_{c}^{\prime}+\theta_{g} S_{g}^{\prime}\right)\left(D^{H}+D^{F}\right)
$$

which appears to be positive: The development of non-carbon energy sources never increases world CO2 emissions.

\section{F Imperfect Substitutability of Coal and Gas in the Home Country}

This appendix presents a complement to the analysis of the main text in which the two sources of energy available in the Home country, coal and gas, are imperfectly substitutable.

Energy demand in the Home country is $D^{H}(p)$, where $p$ is the consumer price in the Home country. It is a CES index of demand for coal $D_{c}^{H}$ and demand for gas $D_{g}^{H}$ :

$$
D^{H}=2\left[\frac{1}{2}\left(D_{c}^{H 1-\frac{1}{\sigma}}+D_{g}^{H 1-\frac{1}{\sigma}}\right)\right]^{\frac{1}{1-\frac{1}{\sigma}}},
$$

where $\sigma>0$ is the elasticity of substitution between coal and gas in domestic demand.

For any given level of energy consumption $D^{H}$, households in the Home country choose the structure of their consumption, that is its allocation between coal and gas, in such a way as to minimize their energy bill:

$$
\min _{D_{c}^{H}, D_{g}^{H}}\left[\left(p_{c}+\theta_{c} \tau^{H}\right) D_{c}^{H}+\left(p_{g}+\theta_{g} \tau^{H}\right) D_{g}^{H}\right]
$$

The necessary first-order conditions for the solution are:

$$
\begin{aligned}
D_{c}^{H} & =\frac{1}{2}\left(\frac{p}{p_{c}+\theta_{c} \tau^{H}}\right)^{\sigma} D^{H}(p), \\
D_{g}^{H} & =\frac{1}{2}\left(\frac{p}{p_{g}+\theta_{g} \tau^{H}}\right)^{\sigma} D^{H}(p), \\
p & =\left[\frac{1}{2}\left(\left(p_{c}+\theta_{c} \tau^{H}\right)^{1-\sigma}+\left(p_{g}+\theta_{g} \tau^{H}\right)^{1-\sigma}\right)\right]^{\frac{1}{1-\sigma}} .
\end{aligned}
$$

As is well known, the tax-inclusive consumer price $p$ is a CES function of coal and gas prices. 
The equilibrium of the gas and coal markets is characterized by:

$$
\begin{gathered}
S_{g}\left(p_{g}\right)=D_{g}^{H}\left(p_{g}, p, \tau^{H}\right) \\
S_{c}\left(p_{c}\right)=S_{c}^{H}\left(p_{c}\right)+S_{c}^{F}\left(p_{c}\right)=D_{c}^{H}\left(p_{c}, p, \tau^{H}\right)+D^{F}\left(p_{c}\right) .
\end{gathered}
$$

Finally, home, foreign and world $\mathrm{CO} 2$ emissions are:

$$
\begin{aligned}
e^{H} & =\theta_{c} D_{c}^{H}\left(p_{c}, p, \tau^{H}\right)+\theta_{g} D_{g}^{H}\left(p_{g}, p, \tau^{H}\right)=\theta_{c}\left(S_{c}\left(p_{c}\right)-D^{F}\left(p_{c}\right)\right)+\theta_{g} S_{g}\left(p_{g}\right), \\
e^{F} & =\theta_{c} D^{F}\left(p_{c}\right), \\
e^{W} & =e^{H}+e^{F}=\theta_{c} S_{c}\left(p_{c}\right)+\theta_{g} S_{g}\left(p_{g}\right) .
\end{aligned}
$$

The system characterizing the equilibrium reads:

$$
\begin{aligned}
p^{1-\sigma} & =\frac{1}{2}\left(\left(p_{c}+\theta_{c} \tau^{H}\right)^{1-\sigma}+\left(p_{g}+\theta_{g} \tau^{H}\right)^{1-\sigma}\right), \\
S_{g}\left(p_{g}\right) & =\frac{1}{2}\left(\frac{p}{p_{g}+\theta_{g} \tau^{H}}\right)^{\sigma} D^{H}(p), \\
S_{c}\left(p_{c}\right) & =\frac{1}{2}\left(\frac{p}{p_{c}+\theta_{c} \tau^{H}}\right)^{\sigma} D^{H}(p)+D^{F}\left(p_{c}\right) .
\end{aligned}
$$

Total differentiation of this system yields:

$$
\begin{aligned}
p^{-\sigma} d p & =\frac{1}{2}\left(p_{c}+\theta_{c} \tau^{H}\right)^{-\sigma}\left(d p_{c}+\theta_{c} d \tau^{H}\right)+\frac{1}{2}\left(p_{g}+\theta_{g} \tau^{H}\right)^{-\sigma}\left(d p_{g}+\theta_{g} d \tau^{H}\right), \\
\frac{S_{g}^{\prime}\left(p_{g}\right) d p_{g}}{S_{g}\left(p_{g}\right)} & =\sigma \frac{d p}{p}-\sigma \frac{d p_{g}+\theta_{g} d \tau^{H}}{p_{g}+\theta_{g} \tau^{H}}+\frac{D^{H \prime}(p) d p}{D^{H}(p)}, \\
\frac{R S_{c}^{\prime}\left(p_{c}\right) d p_{c}}{R S_{c}\left(p_{c}\right)} & =\sigma \frac{d p}{p}-\sigma \frac{d p_{c}+\theta_{c} d \tau^{H}}{p_{c}+\theta_{c} \tau^{H}}+\frac{D^{H \prime}(p) d p}{D^{H}(p)},
\end{aligned}
$$

where $R S_{c}\left(p_{c}\right) \equiv S_{c}\left(p_{c}\right)-D^{F}\left(p_{c}\right)$ is the residual supply of coal, available for consumption in the Home country.

Rearranging and introducing elasticities, one obtains:

$$
\begin{aligned}
p^{1-\sigma} \frac{d p}{p} & =\frac{1}{2}\left(p_{c}+\theta_{c} \tau^{H}\right)^{-\sigma} p_{c} \frac{d p_{c}}{p_{c}}+\frac{1}{2}\left(p_{g}+\theta_{g} \tau^{H}\right)^{-\sigma} p_{g} \frac{d p_{g}}{p_{g}} \\
& +\frac{1}{2}\left[\left(p_{c}+\theta_{c} \tau^{H}\right)^{-\sigma} \theta_{c}+\left(p_{g}+\theta_{g} \tau^{H}\right)^{-\sigma} \theta_{g}\right] d \tau^{H}, \\
\xi_{S_{g}} \frac{d p_{g}}{p_{g}} & =\left(\sigma-\xi_{D^{H}}\right) \frac{d p}{p}-\sigma \frac{d p_{g}+\theta_{g} d \tau^{H}}{p_{g}+\theta_{g} \tau^{H}}, \\
\delta_{c} \frac{d p_{c}}{p_{c}} & =\left(\sigma-\xi_{D^{H}}\right) \frac{d p}{p}-\sigma \frac{d p_{c}+\theta_{c} d \tau^{H}}{p_{c}+\theta_{c} \tau^{H}},
\end{aligned}
$$

where the new notation $\delta_{c}$ denotes the price elasticity of the residual coal supply $R S_{c}$ defined above.

In the neighborhood of the laissez-faire equilibrium in which $\tau^{H}=0$, we finally obtain:

$$
\begin{aligned}
p^{1-\sigma} \frac{d p}{p} & =\frac{1}{2} p_{c}^{1-\sigma} \frac{d p_{c}}{p_{c}}+\frac{1}{2} p_{g}^{1-\sigma} \frac{d p_{g}}{p_{g}}+\frac{1}{2}\left[p_{c}^{1-\sigma} \frac{\theta_{c}}{p_{c}}+p_{g}^{1-\sigma} \frac{\theta_{g}}{p_{g}}\right] d \tau^{H}, \\
\left(\sigma+\xi_{S_{g}}\right) \frac{d p_{g}}{p_{g}} & =\left(\sigma-\xi_{D^{H}}\right) \frac{d p}{p}-\sigma \frac{\theta_{g}}{p_{g}} d \tau^{H}, \\
\left(\sigma+\delta_{c}\right) \frac{d p_{c}}{p_{c}} & =\left(\sigma-\xi_{D^{H}}\right) \frac{d p}{p}-\sigma \frac{\theta_{c}}{p_{c}} d \tau^{H} .
\end{aligned}
$$


That is, in matrix form:

$$
\left(\begin{array}{ccc}
\frac{1}{2} p_{c}^{1-\sigma} & \frac{1}{2} p_{g}^{1-\sigma} & -\frac{1}{2}\left(p_{c}^{1-\sigma}+p_{g}^{1-\sigma}\right) \\
0 & \sigma+\xi_{S_{g}} & \xi_{D^{H}}-\sigma \\
\sigma+\delta_{c} & 0 & \xi_{D^{H}}-\sigma
\end{array}\right)\left(\begin{array}{c}
\frac{d p_{c}}{p_{c}} \\
\frac{d p_{g}}{p_{g}} \\
\frac{d p}{p}
\end{array}\right)=\left(\begin{array}{c}
-\frac{1}{2}\left[p_{c}^{1-\sigma} \frac{\theta_{c}}{p_{c}}+p_{g}^{1-\sigma} \frac{\theta_{g}}{p_{g}}\right] \\
-\sigma \frac{\theta_{g}}{p_{g}} \\
-\sigma \frac{\theta_{c}}{p_{c}}
\end{array}\right) d \tau^{H}
$$

Inverting this system, and using the notation

$$
D \equiv p_{c}^{1-\sigma}\left(\xi_{D^{H}}+\delta_{c}\right)\left(\xi_{S_{g}}+\sigma\right)+p_{g}^{1-\sigma}\left(\xi_{D^{H}}+\xi_{S_{g}}\right)\left(\delta_{c}+\sigma\right)>0,
$$

we obtain:

$$
\begin{aligned}
\frac{d p_{c} / p_{c}}{d \tau^{H}} & =\frac{1}{D}\left[-2 p^{1-\sigma} \frac{\theta_{c}}{p_{c}} \xi_{D^{H}} \sigma-\left(p_{c}^{1-\sigma} \frac{\theta_{c}}{p_{c}}+p_{g}^{1-\sigma} \frac{\theta_{g}}{p_{g}}\right) \xi_{D^{H}} \xi_{S_{g}}-p_{g}^{1-\sigma}\left(\frac{\theta_{c}}{p_{c}}-\frac{\theta_{g}}{p_{g}}\right) \sigma \xi_{g}^{H}\right], \\
\frac{d p_{g} / p_{g}}{d \tau^{H}} & =\frac{1}{D}\left[-2 p^{1-\sigma} \frac{\theta_{g}}{p_{g}} \xi_{D^{H}} \sigma-\left(p_{c}^{1-\sigma} \frac{\theta_{c}}{p_{c}}+p_{g}^{1-\sigma} \frac{\theta_{g}}{p_{g}}\right) \xi_{D^{H}} \delta_{c}+p_{c}^{1-\sigma}\left(\frac{\theta_{c}}{p_{c}}-\frac{\theta_{g}}{p_{g}}\right) \sigma \delta_{c}\right], \\
\frac{d p / p}{d \tau^{H}} & =\frac{1}{D}\left[p_{c}^{1-\sigma} \frac{\theta_{c}}{p_{c}} \delta_{c}\left(\xi_{S_{g}}+\sigma\right)+p_{g}^{1-\sigma} \frac{\theta_{g}}{p_{g}} \xi_{S_{g}}\left(\delta_{c}+\sigma\right)\right] .
\end{aligned}
$$

Using the notation

$$
\pi \equiv \frac{p_{c}^{1-\sigma}}{p_{g}^{1-\sigma}}=\left(\frac{D_{c}^{H}}{D_{g}^{H}}\right)^{1-\frac{1}{\sigma}},
$$

the previous system may be rewritten as:

$$
\begin{aligned}
\frac{d p_{c} / p_{c}}{d \tau^{H}} & =\frac{p_{c}}{D p_{g}^{1-\sigma} \theta_{g}}\left[-\frac{\theta_{c}}{\theta_{g}}\left((1+\pi) \xi_{D^{H}} \sigma+\pi \xi_{D^{H}} \xi_{S_{g}}+\sigma \xi_{S_{g}}\right)+\pi^{\frac{1}{1-\sigma}} \xi_{S_{g}}\left(\sigma-\xi_{D^{H}}\right)\right] \\
\frac{d p_{g} / p_{g}}{d \tau^{H}} & =\frac{p_{c}}{D p_{g}^{1-\sigma} \theta_{g}}\left[\frac{\theta_{c}}{\theta_{g}}\left(\sigma-\xi_{D^{H}}\right) \pi \delta_{c}-\pi^{\frac{1}{1-\sigma}}\left((1+\pi) \xi_{D^{H}} \sigma+\xi_{D^{H}} \delta_{c}+\pi \sigma \delta_{c}\right)\right] \\
\frac{d p / p}{d \tau^{H}} & =\frac{p_{c}}{D p_{g}^{1-\sigma} \theta_{g}}\left[\frac{\theta_{c}}{\theta_{g}} \pi \delta_{c}\left(\xi_{S_{g}}+\sigma\right)+\pi^{\frac{1}{1-\sigma}} \xi_{S_{g}}\left(\delta_{c}+\sigma\right)\right] .
\end{aligned}
$$

Equation (F.15) shows that the energy consumer price in the Home country unambiguously increases with the tax.

We assume, for simplicity, that the price elasticity of coal supply $\xi_{S_{c}}$ is the same in the Home country and in the Foreign country.

Changes in home, foreign and world emissions are given by:

$$
\begin{aligned}
& \frac{d e^{H}}{d \tau^{H}}=\theta_{c} D_{c}^{H} \delta_{c} \frac{d p_{c} / p_{c}}{d \tau^{H}}+\theta_{g} S_{g} \xi_{S_{g}} \frac{d p_{g} / p_{g}}{d \tau^{H}}, \\
& \frac{d e^{F}}{d \tau^{H}}=-\theta_{c} D^{F} \xi_{D^{F}} \frac{d p_{c} / p_{c}}{d \tau^{H}}, \\
& \frac{d e^{W}}{d \tau^{H}}=\theta_{c} S_{c} \xi_{S_{c}} \frac{d p_{c} / p_{c}}{d \tau^{H}}+\theta_{g} S_{g} \xi_{S_{g}} \frac{d p_{g} / p_{g}}{d \tau^{H}},
\end{aligned}
$$

where $\delta_{c}=\frac{S_{c}}{S_{c}-D^{F}} \xi_{S_{c}}+\frac{D^{F}}{S_{c}-D^{F}} \xi_{D^{F}}=\frac{1}{D_{c}^{H}}\left(S_{c} \xi_{S_{c}}+D^{F} \xi_{D^{F}}\right)$. 


\section{Effect of the Tax on the Domestic Energy Price and Consumption}

As already noticed, according to equation (F.15), $\frac{d p / p}{d \tau^{H}}>0$. Then,

$$
\frac{d D^{H}(p) / D^{H}(p)}{d \tau^{H}}=-\xi_{D^{H}} \frac{d p / p}{d \tau^{H}}<0 .
$$

The domestic energy price increases and domestic energy use decreases with the tax.

The next step is to determine how the structure of energy consumption changes, given that coal is more polluting than gas.

\section{Effect of the Tax on Gas Production}

Totally differentiating the equation defining gas supply yields:

$$
\frac{d S_{g}\left(p_{g}\right) / S_{g}\left(p_{g}\right)}{d \tau^{H}}=\xi_{S_{g}} \frac{d p_{g} / p_{g}}{d \tau^{H}} .
$$

From equation (F.14), one can easily obtain

$$
\frac{d p_{g} / p_{g}}{d \tau^{H}}>0 \Longleftrightarrow\left\{\begin{array}{l}
\sigma>\xi_{D^{H}} \\
\frac{\theta_{c}}{\theta_{g}}>\pi^{\frac{\sigma}{1-\sigma}} \frac{\pi \sigma\left(\xi_{D^{H}}+\delta_{c}\right)+\xi_{D^{H}}\left(\sigma+\delta_{c}\right)}{\delta_{c}\left(\sigma-\xi_{D^{H}}\right)} .
\end{array}\right.
$$

In the rest of the analysis, we will focus on empirically relevant situations in which the elasticity of substitution between coal and gas in the domestic energy demand is sufficiently large. Precisely, we assume that it is larger than the price elasticity of domestic energy demand:

$$
\sigma>\xi_{D^{H}}
$$

When $\sigma \mapsto \infty, \pi \mapsto \frac{D_{c}^{H}}{D_{g}^{H}}$ and condition (F.19) reduces to:

$$
\frac{\theta_{c}-\theta_{g}}{\theta_{g}}>\frac{(1+\pi) \xi_{D^{H}}}{\pi \delta_{c}}=\frac{D^{H} \xi_{D^{H}}}{S_{c} \xi_{S_{c}}+D^{F} \xi_{D^{F}}}
$$

which is condition (7) in the main text.

In the general case, in equilibrium, the gas producer price and gas supply are more likely to increase when $\theta_{g}$ is relatively low compared to $\theta_{c}$.

It is also more likely to increase when $\xi_{D^{H}}$ is low: The right-hand side of condition (F.19) is increasing with $\xi_{D^{H}}$. At the limit, when $\xi_{D^{H}} \mapsto 0$, condition (F.19) reads:

$$
\frac{\theta_{c}}{\theta_{g}}>\pi^{\frac{1}{1-\sigma}}=\left(\frac{D_{g}^{H}}{D_{c}^{H}}\right)^{\frac{1}{\sigma}} \quad(=1 \quad \text { when } \quad \sigma \mapsto \infty)
$$

If $D_{g}^{H}<D_{c}^{H}$, that is if the share of gas in domestic consumption is small in the initial equilibrium, then $\left(\frac{D_{g}^{H}}{D_{c}^{H}}\right)^{\frac{1}{\sigma}}<1$ for all $\sigma$, meaning that condition (F.19) is always satisfied. If on the contrary $D_{g}^{H}>D_{c}^{H},\left(\frac{D_{g}^{H}}{D_{c}^{H}}\right)^{\frac{1}{\sigma}}$ is greater than 1 and is decreasing with $\sigma$. Condition (F.19) is all the less likely to hold as the initial share of gas is high and $\sigma$ is small.

Finally, the gas producer price and gas supply are more likely to increase when $\xi_{S_{c}}$ is high: The right-hand side of condition (F.19) is decreasing with $\delta_{c}$, itself being increasing with $\xi_{S_{c}}$. 


\section{Effect of the Tax on Coal Production}

Totally differentiating the equation defining coal supply yields:

$$
\frac{d S_{c}\left(p_{c}\right) / S_{c}\left(p_{c}\right)}{d \tau^{H}}=\xi_{S_{c}} \frac{d p_{c} / p_{c}}{d \tau^{H}} .
$$

From equation (F.13), one can see

$$
\frac{d p_{c} / p_{c}}{d \tau^{H}}<0 \Longleftrightarrow \frac{\theta_{c}}{\theta_{g}}>\frac{\pi^{\frac{1}{1-\sigma}} \xi_{S_{g}}\left(\sigma-\xi_{D^{H}}\right)}{\pi \xi_{D^{H}}\left(\sigma+\xi_{S_{g}}\right)+\sigma\left(\xi_{D^{H}}+\xi_{S_{g}}\right)} .
$$

When this condition holds, $\frac{d e^{F}}{d \tau^{H}}>0$ : There is carbon leakage.

When $\sigma \mapsto \infty$, condition (F.20) reduces to:

$$
\frac{\theta_{c}}{\theta_{g}}>\frac{\xi_{S_{g}}}{(1+\pi) \xi_{D^{H}}+\xi_{S_{g}}}=\frac{S_{g} \xi_{S_{g}}}{D^{H} \xi_{D^{H}}+S_{g} \xi_{S_{g}}}
$$

which is always satisfied.

In general, condition (F.20) may not be satisfied, meaning that the introduction of a CO2 tax in the Home country may not cause carbon leakage. It is in particular the case for a small elasticity of substitution of coal and gas and a large share of gas in energy demand in the initial equilibrium. When it is not satisfied, condition (F.19) is not satisfied either: The gas producer price decreases. One can easily see this in the case in which $\xi_{D^{H}} \mapsto 0$ : Then, conditions (F.19) and (F.20) coalesce into:

$$
\frac{\theta_{c}}{\theta_{g}}>\pi^{\frac{1}{1-\sigma}}=\left(\frac{D_{g}^{H}}{D_{c}^{H}}\right)^{\frac{1}{\sigma}}
$$

For $D_{c}^{H}>D_{g}^{H}$, it is satisfied for all $\sigma$. For $D_{c}^{H}<D_{g}^{H}$ and $\sigma<1$, it may not be satisfied, since the right-hand side of the condition may become very high.

This is the main reason why departing from the perfect substitutability assumption may significantly modify the analysis. In this paper, however, we are interested in the empirically relevant situations in which coal is initially more used than gas in the initial equilibrium.

\section{Effect of the Tax on Home Emissions and Coal Exports}

Using equations (F.16), (F.13) and (F.14) we obtain:

$$
\begin{aligned}
\frac{d e^{H}}{d \tau^{H}}= & \frac{p_{c} D_{c}^{H} \delta_{c}}{D p_{g}^{1-\sigma}}\left[-\left(\frac{\theta_{c}}{\theta_{g}}\right)^{2}\left((1+\pi) \xi_{D^{H}} \sigma+\pi \xi_{D^{H}} \xi_{S_{g}}+\sigma \xi_{S_{g}}\right)\right. \\
& \left.+\frac{\theta_{c}}{\theta_{g}}\left(\pi^{\frac{1}{1-\sigma}} \xi_{S_{g}}+\alpha \pi \delta_{c}\right)\left(\sigma-\xi_{D^{H}}\right)-\alpha \pi^{\frac{1}{1-\sigma}}\left((1+\pi) \xi_{D^{H}} \sigma+\xi_{D^{H}} \delta_{c}+\pi \sigma \delta_{c}\right)\right],
\end{aligned}
$$

where $\alpha \equiv \frac{S_{g} \xi_{S_{g}}}{D_{c}^{H} \delta_{c}}$. 
Then, domestic emissions decrease with the tax if and only if

$$
\begin{aligned}
Q\left(\frac{\theta_{c}}{\theta_{g}}\right)= & -\left(\frac{\theta_{c}}{\theta_{g}}\right)^{2}\left((1+\pi) \xi_{D^{H}} \sigma+\pi \xi_{D^{H}} \xi_{S_{g}}+\sigma \xi_{S_{g}}\right)+\frac{\theta_{c}}{\theta_{g}}\left(\pi^{\frac{1}{1-\sigma}} \xi_{S_{g}}+\alpha \pi \delta_{c}\right)\left(\sigma-\xi_{D^{H}}\right) \\
& -\alpha \pi^{\frac{1}{1-\sigma}}\left((1+\pi) \xi_{D^{H}} \sigma+\xi_{D^{H}} \delta_{c}+\pi \sigma \delta_{c}\right)<0 .
\end{aligned}
$$

When $\sigma \mapsto \infty$, condition (F.22) reduces to:

$$
Q\left(\frac{\theta_{c}}{\theta_{g}}\right)=-\left(\frac{\theta_{c}}{\theta_{g}}\right)^{2} \xi_{S_{g}}\left(1+\frac{D^{H} \xi_{D^{H}}}{D_{g}^{H} \xi_{S_{g}}}\right)+\frac{\theta_{c}}{\theta_{g}} 2 \xi_{S_{g}}-\xi_{S_{g}}\left(1+\frac{D^{H} \xi_{D^{H}}}{D_{c}^{H} \delta_{c}}\right)<0 .
$$

One can see that the discriminant of the equation $Q\left(\frac{\theta_{c}}{\theta_{g}}\right)=0$ is always strictly negative. Moreover, $Q(1)<0$. Therefore $Q\left(\frac{\theta_{c}}{\theta_{g}}\right)$ is strictly negative for all $\frac{\theta_{c}}{\theta_{g}} \geq 1$. We recover the result of the main text: When coal and gas are perfect substitutes, domestic emissions always decrease with the $\mathrm{CO} 2$ tax.

When $\sigma \mapsto \xi_{D^{H}}$, we also obtain $Q\left(\frac{\theta_{c}}{\theta_{g}}\right)<0$ for all $\frac{\theta_{c}}{\theta_{g}} \geq 1$.

Finally, coal exports by the Home country are: $S_{c}^{H}-D_{c}^{H}=D_{c}^{F}\left(p_{c}\right)-S_{c}^{F}\left(p_{c}\right)$. Therefore, they increase when the producer price of coal decreases, and vice versa.

\section{Effect of the Tax on World Emissions}

From equation (F.18), it follows that world emissions increase with the tax (more-than$100 \%$ leakage) if and only if

$$
\begin{aligned}
R\left(\frac{\theta_{c}}{\theta_{g}}\right)= & -\left(\frac{\theta_{c}}{\theta_{g}}\right)^{2} \pi^{\frac{1}{1-\sigma}}\left[\pi \xi_{D^{H}}\left(\sigma+\xi_{S_{g}}\right)+\sigma\left(\xi_{D^{H}}+\xi_{S_{g}}\right)\right] \\
& +\left(\frac{\theta_{c}}{\theta_{g}}\right)\left(\sigma-\xi_{D^{H}}\right)\left[\xi_{S_{g}}+\beta \pi^{\frac{\sigma}{1-\sigma}} \delta_{c}\right]-\beta\left[\pi \sigma\left(\xi_{D^{H}}+\delta_{c}\right)+\xi_{D^{H}}\left(\sigma+\delta_{c}\right)\right]>0
\end{aligned}
$$

where $\beta \equiv \frac{S_{g} \xi_{S_{g}}}{S_{c} \xi_{S_{c}}}$.

When $\sigma \mapsto \infty$ condition (F.23) corresponds to equation (10) in the main text.

\section{Illustrative Numerical Simulations}

We perform numerical simulations for different levels of the elasticity of substitution between coal and gas $\sigma$. Parameters' values are the same as in the main text, as given in Table 1, except for the price elasticity of coal supply, which we purposely take very low (equal to 0.1 ) so as to illustrate cases with a more-than-100\% leakage rate. Our values satisfy conditions (F.19), (F.20) and (F.22). For each value of $\sigma, D_{g}^{H}$ is calculated using equation (F.1), and $S_{g}=D_{g}^{H}$. Besides, to ensure coherence with the main text, condition (F.23) is re-written using $r=\frac{\theta_{c}-\theta_{g}}{\theta_{g}}$ as variable instead of $\frac{\theta_{c}}{\theta_{g}}$, such that $P(r)=R\left(\frac{\theta_{c}}{\theta_{g}}\right)$. Figure 9 shows the results.

Remember that there is more-than- $100 \%$ leakage for the values of $r$ such that $P(r)>0$. It never occurs for $\sigma=0.8$ and $\sigma=1$, but it does occur for $\sigma=5$ and $\sigma=10$ (which can be considered here as "close to infinity"). Therefore the possibility that the leakage 


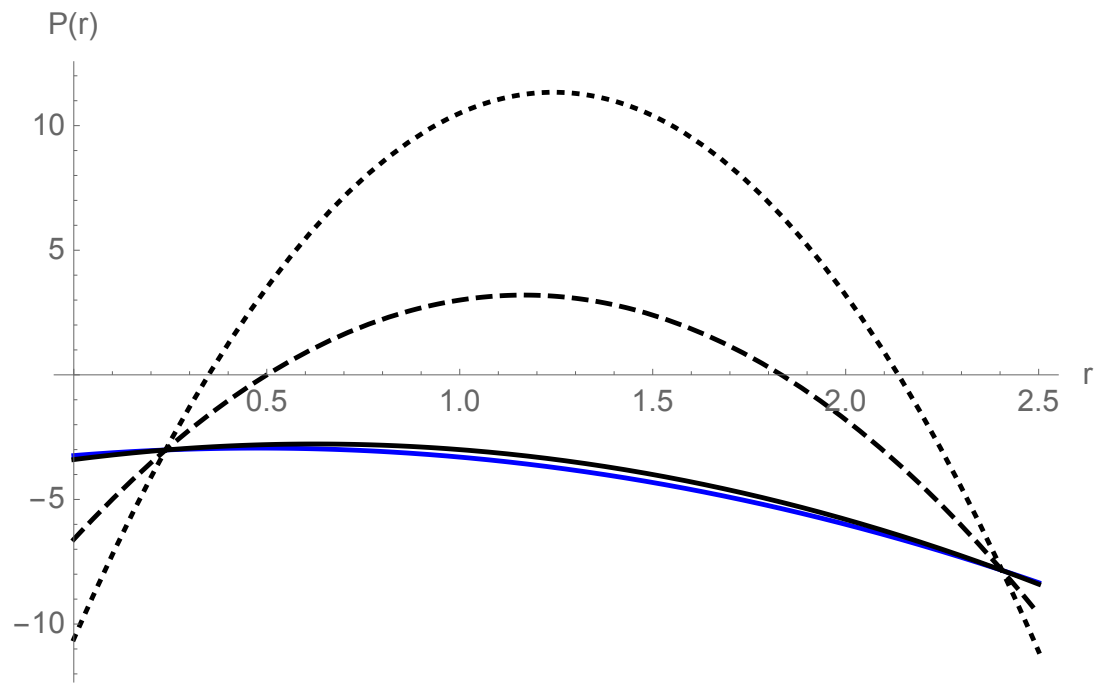

Figure 9: Illustration of condition (F.23) -blue: $\sigma=0.8$; black, plain: $\sigma=1$; black, dashed: $\sigma=5$; black, dotted: $\sigma=10$

rate induced by the unilateral CO2 reduction policy exceeds $100 \%$ carries over when coal and gas are imperfect substitutes, but the smaller the elasticity of substitution the less plausible it is. 